\title{
Overweight adolescents in West Virginia report healthier diet choices after a two-week residential camp
}

Heidi Jo Schoeppner

West Virginia University

Follow this and additional works at: https://researchrepository.wvu.edu/etd

\section{Recommended Citation}

Schoeppner, Heidi Jo, "Overweight adolescents in West Virginia report healthier diet choices after a twoweek residential camp" (2009). Graduate Theses, Dissertations, and Problem Reports. 2782.

https://researchrepository.wvu.edu/etd/2782

This Thesis is protected by copyright and/or related rights. It has been brought to you by the The Research Repository @ WVU with permission from the rights-holder(s). You are free to use this Thesis in any way that is permitted by the copyright and related rights legislation that applies to your use. For other uses you must obtain permission from the rights-holder(s) directly, unless additional rights are indicated by a Creative Commons license in the record and/ or on the work itself. This Thesis has been accepted for inclusion in WVU Graduate Theses, Dissertations, and Problem Reports collection by an authorized administrator of The Research Repository @ WVU. For more information, please contact researchrepository@mail.wvu.edu. 


\title{
Overweight Adolescents in West Virginia Report Healthier Diet Choices after a Two-Week Residential Camp
}

\section{Heidi Jo Schoeppner}

Thesis submitted to the College of Agriculture, Forestry and Consumer Sciences

at West Virginia University in partial fulfillment of requirements

for the Degree of

Master of Science

in

Animal Nutritional Sciences

\author{
Cindy Fitch, Ph.D., R.D., Chair \\ Janet Tou, Ph.D. \\ Sean Bulger, Ed.D. \\ Department of Animal and Nutritional Sciences
}

Morgantown, West Virginia

2009

Keywords: adolescent, overweight, nutrition education, residential camp, intervention, obesity 


\section{ABSTRACT \\ Overweight Adolescents in West Virginia Report Healthier Diet Choices after a Two-Week Residential Camp}

\section{Heidi Jo Schoeppner}

As the number of overweight adolescents in the United States continues to grow, effective methods of treatment intervention need to be established. The objective of this study was to determine if various methods of nutrition education is an effective approach to teach overweight 10-14 year-old adolescents (BMI $\geq 85^{\text {th }}$ percentile on the CDC's growth charts) in West Virginia to make healthier food choices. Twenty-four adolescents were recruited through schools, physician offices, and community programs to attend a two-week residential lifestyle-modification camp with three follow-up weekends over the next 12 months. Prior to attending the initial camp session, subjects were asked to complete a three-day diet journal. Three-months later, subjects were asked to complete a three-day diet journal before coming to the first follow-up weekend. While attending the camp session, subjects participated in four, 50 minute nutrition education lessons focusing on the Plate Method and 'Always' food choices vs. 'Sometimes' or 'Sparing' food choices. Only subjects with recorded pre- and post-camp diet journals were analyzed to determine statistical significance $(\mathrm{N}=10)$. Diet records prior to camp indicated that on average subjects were not meeting recommendations for servings of fruits, vegetables, milk, or whole grains, but were exceeding recommendations for soda/sweetened drinks and high fat/sugar foods. Diet records at follow-up indicate that on average subjects significantly increased fruit intake $(\mathrm{P}<0.05)$ and significantly decreased soda/sweetened drink intake $(\mathrm{P}<0.05)$ when compared to pre-camp diet journals. Diet records at follow-up indicate improvement in the number of times subjects reported eating vegetables, whole grains, and not eating high fat/sugar foods. No difference was noted in water consumption. Using a two-week residential camp to provide nutrition education is an effective way to help overweight adolescents make healthier food choices at snack- and meal-times. 


\section{ACKNOWLEDGMENTS}

I would like to start by thanking the members of my committee, Dr. Cindy Fitch, Dr. Sean Bulger, and Dr. Janet Tou, thank you for your advice, support, and for your time in serving on my committee.

A special thank you to the 2009 Class of Dietetic Interns, thank you for all your help and hard work in making the nutrition component of camp a success!

I thank my wonderful friends for their continued support, encouragement and especially for their sense of humor.

I thank my family for their ever flowing words of encouragement, not only through this journey, but through all of life's many journeys. I thank you for your love and understanding, and I thank you for your help in becoming the women I am today.

Lastly, I dedicate this to my parents, Pat and Krista, for their unconditional love and support. Thank you for teaching me that I am limited only by my imagination, thank you for teaching me the value of hard-work, perseverance and laughter, and most of all thank you for being the voice of reason on the other end of the phone throughout this especially challenging journey. 


\section{TABLE OF CONTENTS}

ABSTRACT ii

List of Tables $\quad$ vi

List of Appendices vii

CHAPTER1: Introduction 1

CHAPTER 2: Review of Literature 3

1. Definition and Assessment of Overweight and Obesity 3

2. Childhood Overweight as a Public Health Concern 4

3. Economic Costs of Childhood Overweight 6

4. Childhood Overweight in West Virginia 8

5. Dietary Recommendations 10

6. Physical Activity and the Neighborhood 12

7. Treatments of Child and Adolescent Overweight 13

7.1 Individual- and Family-Based Treatment 13

7.2 School-Based Treatment 14

7.3Community-Based Treatment 15

$\begin{array}{ll}\text { Statement of the Problem } & 18\end{array}$

$\begin{array}{ll}\text { Hypothesis } & 19\end{array}$

$\begin{array}{ll}\text { CHAPTER 3: Objectives of study } & 20\end{array}$

$\begin{array}{ll}\text { Subjects } & 20\end{array}$

$\begin{array}{ll}\text { Intervention } & 20\end{array}$

$\begin{array}{ll}\text { Data Collection } & 24\end{array}$

$\begin{array}{ll}\text { Measurements } & 24\end{array}$ 
Data Analysis

CHAPTER 4: Results 28

CHAPTER 5: Discussion 31

CHAPTER 6: Conclusion 36

Literature Cited 38

Appendices 


\section{List of Tables}

Table 1: Potential Complications of Childhood Overweight 5

Table 2: Take Charge, Be Healthy Pre- Post- Knowledge Nutrition Quiz Results 28

Table 3: Subjects Pre-camp Recorded Average Dietary Intake 29

Table 4: Subjects Pre- and Post-camp Recorded Average Dietary Intake 30 


\section{List of Appendices}

Appendix 1: 2000 CDC Growth Chart for Boys 2-20 years 41

Appendix 2: 2000 CDC Growth Chart for Girls 2-20 years 43

Appendix 3: Take Charge, Be Healthy Pre- Post- Nutrition Knowledge Quiz 45

Appendix 4: The Portion Plate 51

Appendix 5: Nutrition Lesson One, Portion Control 52

Appendix 6: Nutrition Lesson Two, Energy Balance and Nutrition 53

Appendix 7: Nutrition Lesson Three, Food Labels 54

Appendix 8: Grocery Store Tour Outline 55

Appendix 9: Instructions for completing an accurate daily food record 58

Appendix 10: Camp NEW You Master Schedule $\quad 60$

Appendix 11: Camp NEW You Cookbook 2008 


\section{CHAPTER 1 \\ INTRODUCTION}

Within the past few decades the prevalence of adolescent overweight has increased more than three-fold. The dramatic increase in the prevalence of overweight youth in the United States has become an important public health concern (Singh et al., 2007). It is estimated that approximately 17.5 percent of the 6 to 11 year old population and 17.0 percent of the 12 to 17 year old population is overweight in the United States (National Center for Health Statistics, 2007; Singh et al., 2007). Overweight children and adolescents are particularly prevalent in West Virginia, as is adult overweight and obesity. This is one reason why West Virginia is an ideal setting to pilot the success of weight-loss programs such as a residential weight-loss camp for adolescents.

The dramatic increase in the prevalence of overweight youth in the United States has become an important public health concern (Singh et al. 2007). Approximately one third of overweight preschool children, one half of overweight school children, and threequarters of overweight teenagers grow up to be obese as adults (Serdula et al. 1993; Whitaker et al. 1997). This is important because overweight or obese adults commonly suffer from comorbidities associated with their weight. In the year 2001 alone, it was estimated that the direct and indirect costs of overweight and obesity were \$139 billion dollars (Finkelstein et al. 2005). As the number of children and adolescents entering adulthood as overweight or obese increases, the cost of treating weight-related conditions is also likely to escalate. Successful implementation of a residential weight-loss camp for children and adolescents may help to decrease health-care costs as well as improve the quality of life enjoyed by the camp's participants. 
A family-based treatment for overweight has the potential to most effectively reach children and adolescents, and therefore has the greatest potential to positively affect their lifestyle behaviors (ADA, 2006). Parental involvement in the treatment intervention leads to more positive outcomes within the treatment group (Golan and Crow, 2004). Therefore, multi-component residential weight-loss camps with parental involvement may be an effective form of family-based treatment. Currently, the available research in this area is limited.

The objective of the proposed study is to determine the effectiveness of a twoweek residential weight-loss camp, with 12 months of follow-up, for overweight 10 to 14 year old boys and girls in West Virginia. 


\section{CHAPTER 2}

\section{REVIEW OF LITERATURE}

\section{Definition and Assessment of Overweight and Obesity}

Overweight is defined as a weight generally considered to be greater than recommended for a given height and age (CDC, 2007). Overweight is generally the result of consuming more calories than the number of calories expended, most days of the week. Overweight identifies a range of weight shown to increase the likelihood of developing weight-related health conditions. Overweight is assessed by determining a person's body-mass index (BMI) score. In children and adolescents, BMI scores were designed to account for variations in body fatness at different ages/ stages of development and for variations in body fatness between boys and girls. BMI is also referred to as 'BMI-for-age' when referring to children and adolescent scores.

Children "at risk of overweight" is defined as a BMI measurement at the $85^{\text {th }}$ and less than the $95^{\text {th }}$ percentile, as set by the 2000 Center for Disease Control growth charts for age and gender (NCHS, 2007; CDC, 2007). A BMI measurement at or above the $95^{\text {th }}$ percentile for age and gender of the growth charts is considered "overweight" (CDC, 2007). "Normal weight" for children is defined as a BMI at or above the $5^{\text {th }}$ percentile and below the $85^{\text {th }}$ percentile on the growth charts (CDC, 2007; ADA, 2006). BMI-forage does not include a classification of "obese" (NCHS 2005; CDC, 2007). BMI is a screening tool that can be used to estimate body fatness in people of all ages, but further assessments should be completed by a physician before classifying children as "at risk of overweight" or "overweight" (CDC, 2007). BMI is considered a reliable estimate of body fatness for most people. BMI measurements tend to overestimate body fat in individuals 
who are very muscular, and underestimate body fat in individuals who have lost muscle mass (USDHHS/USDA, 2005). BMI adjusts bodyweight for height in kilograms per meters squared (kilograms/meters ${ }^{2}$ ) (NCHS, 2007). BMI is to be used as an estimator and not as an absolute value/classification.

\section{Childhood Overweight as a Public Health Concern}

As children's body weight increases, the prevalence of serious weight-associated health conditions also increase (Ebbeling et al., 2002; Ludwig, 2007). The prevalence of medical conditions such as hypertension, insulin resistance/ type 2 diabetes mellitus, gastroesophageal reflux, asthma, dyslipidemia, and heart disease, once rarely seen in children and adolescents have become a common diagnosis for today's youth (ADA, 2006; Ebbeling et al., 2002; Ludwig, 2007). Strong et al. (1992) reported fatty streaks in the arteries of a 13 year-old adolescent. Table 1 below, lists some metabolic and psychosocial (emotional) complications that may be associated with childhood overweight or obesity. 
Table 1. Potential Complications of Childhood Overweight

\begin{tabular}{|l|l|}
\hline Neurological & Pseudotumor cerebri \\
\hline Endocrine & Insulin resistance \\
& Type 2 Diabetes Mellitus \\
& Precocious Puberty \\
& Polycystic Ovary Syndrome (girls) \\
& Hypogonadism (boys) \\
\hline Cardiovascular & Dyslipidemia \\
& Hypertension \\
& Chronic Inflammation \\
& Endothelial Dysfunction \\
\hline Pulmonary & Sleep Apnea \\
& Asthma \\
& Exercise Intolerance \\
\hline Gastrointestinal & Gastroesophageal Reflux \\
& Steatohepatitis \\
& Gallstones \\
Constipation
\end{tabular}

Table adapted from Ebbling et al. (2002) and Ludwig (2007).

Precocious puberty, or advanced sexual maturation, can be seen in both overweight boys and girls (ADA, 2006). The occurrence of early maturation is most commonly observed in conjunction with severe overweight status. Insulin resistance, an increase in the amount of circulating insulin-like growth factors, polycystic ovary syndrome, and exaggerated adrenal response have been shown to be associated with precocious puberty. A study by Wilcox et al. (1988) reported associations with hormonal imbalances and overweight during puberty with growth plate (epiphysis) injuries. 
Advanced bone age and higher levels of circulating sex hormones are also associated with a childhood status of overweight (ADA, 2006). With the early onset of puberty in girls comes a heightened lifetime exposure to estrogen, which may increase their risk of developing breast cancer and possibly ovarian cancer later in life.

In addition to the comorbidities listed above, overweight and obese children frequently suffer from psychosocial distress related to their weight (Table 1). Children often suffer from feelings of social isolation, anxiety, and elevated rates of disordered eating patterns (Ludwig, 2007). Overweight children are frequently subjected to teasing and ridicule by their peers, teachers, and even members of their own family (ADA, 2006). This type of discrimination may begin at an early age and continue throughout adolescence and into adulthood. Children suffering from low self-esteem, depression, and/or social isolation due to their weight are more likely to live in poverty and not as likely to graduate college when compared to their thinner peers (Ludwig, 2007). For both physical and psychological health reasons, it is important to investigate and document interventions designed to prevent and treat overweight in children and adolescents.

\section{Economic Costs of Childhood Overweight}

The monetary costs of childhood overweight are not well documented. Ludwig (2007) estimates the yearly economic cost of childhood overweight at several hundred million dollars. Approximately $80 \%$ of children who are overweight at $10-15$ years of age are obese adults at the age of 25 years (Whitaker et al., 1997). The estimated costs of childhood obesity is relatively small; however as overweight children become adults, the cost of healthcare and loss of worker productivity due to overweight and obesity increases (Finkelstein et al., 2005; Ludwig, 2007). Adult obesity was determined to be 
more severe in children found to be overweight prior to 8 years of age (Freedman et al., 2001). Finkelstein et al. (2005) documented an $88 \%$ increase in the number of doctor visits from 1988 to 1994 due to obesity-related conditions in adults. Lost wages and loss of productivity due to illness or doctor visits associated with overweight and obesity have been identified. It is estimated that in 1998 employers lost $\$ 2.4$ billion dollars attributable to obesity-related absenteeism. In 2001, it was estimated that the direct and indirect costs of overweight and obesity were $\$ 139$ billion dollars per year. These statistics are likely to worsen as more adolescents enter adulthood as overweight or obese. The obesity-related conditions children and adolescents carry into adulthood will likely remain or worsen in severity. In addition, the threat of developing additional health complications due to overweight or obesity can be expected.

As overweight children and adolescents become adults, the complications associated with their weight do not disappear. Frequently, these complications multiply and/or become compounded as overweight children and adolescents achieve adulthood as overweight or obese adults. This can have significant implications regarding morbidity and mortality. Baker et al. (2007) identified a direct relationship between childhood BMI and coronary heart disease (CHD) risk in adulthood. Baker et al. (2007) studied a cohort of 276,835 Danish school children (7-13 years of age) born between 1930 and 1976. Information to calculate the children's BMI was obtained from the Copenhagen School Health Records Register. CHD in adulthood (25 years of age or older) information was obtained through the National Civil Register of vital statistics. Results of this study show a direct linear relationship between CHD and BMI for boys at 7-13 years of age and for girls at 10-13 years of age. As childhood BMI increased, risk for CHD in adulthood 
increased. The risk for CHD in adulthood also increased with childhood age and after statistical adjustment for birth weight. However, statistical levels of significance were not reported for this study. Similarly, Bibbins-Domingo et al. (2007) examined adolescents between 12 and 19 years of age and projected an increase in the prevalence of CHD in overweight adolescents at 35 years of age.

The results of these studies demonstrate the importance of preventing and treating overweight in both children and adolescents for physical and psychological health and economic cost.

\section{Childhood Overweight in West Virginia}

Singh et al. (2007) compared obesity rates between states and geographic locations within the United States. All data were obtained from the National Survey of Children's Health (NCHS, 2007) conducted by the National Center for Health Statistics (Singh et al., 2007). The state results of this analysis showed that 10 to 17 year old boys and girls in West Virginia, along with those in Washington, D.C. and Kentucky, were almost three times more likely to be obese than their counterparts in Utah, which recorded the lowest prevalence of obesity for boys and girls combined (8.5\%). This multilevel analysis also reports that children, specifically in the states of West Virginia, Kentucky, Texas, Tennessee, and North Carolina (adjusted prevalence $>18.3 \%$ ), are more than twice as likely to be obese than their counterparts of similar behavioral and socioeconomic status in Utah (adjusted prevalence $=10.4 \%$ ). The United States childhood overweight $(\mathrm{r}=0.52)$, adolescent overweight $(\mathrm{r}=0.60)$ correlated with adult $(\geq 18$ years) obesity. West Virginia, Mississippi, Kentucky, and Tennessee rate among the states with the highest obesity rates for children, adolescents, and adults. In West Virginia, 37.7\% of 
the adult population is overweight (BMI of greater than or equal to 25.0 and less than or equal to 29.9$)$, while $30.3 \%$ of the adult population is obese ( $30.0 \leq$ BMI $\geq 99.8)$ (BRFSS Prevalence Data, 2007). Having an obese parent was found to more than double the risk for adult obesity in overweight and normal-weight children (Whitaker et al., 1997).

Regional patterns were also identified by Singh et al. (2007). After the information was adjusted for age- and sex-adjusted patterns, it was determined that that children in the South Atlantic region (Delaware, Maryland, Washington, D.C., Virginia, West Virginia, North Carolina, South Carolina, Georgia, and Florida) are 49\% more likely to be obese than children in the Mountain region (Montana, Idaho, Wyoming, Colorado, New Mexico, Arizona, Utah, and Nevada). The household's education level, income, and neighborhood social capital were reported to influence a child's risk of obesity. As the level of household education and household income declines, the child's adjusted odds of obesity increases significantly ( $\mathrm{P}<0.05)$. West Virginia is third to Mississippi and Arkansas, respectively, as the nation's states with lowest personal income per capita (U.S. Census Bureau, 2006). The lower the parents' perceived level of social capital, the higher the children's adjusted odds of obesity became $(\mathrm{P}<0.05)$ (Singh et al., 2007). After adjusting for state of residence, socioeconomic status, and behavioral factors, African American children and Hispanic children had a 60\% and 27\%, respectively, higher risk of obesity than their non-Hispanic white peers. Baker et al. (2007) also reports that childhood socioeconomic status and adult risk of CHD have an inverse relationship. It was noted that this relationship weakens when adult socioeconomic status is considered. This study will focus on West Virginia adolescents 
due to the high prevalence of obesity and generally low socioeconomic status in the West Virginia population.

\section{Dietary Recommendations}

The Dietary Guidelines for Americans provide scientific-based recommendations to promote overall health and to reduce the risk for disease through diet and physical activity (USDHHS/USDA, 2005). These recommendations are targeted to the United States general public over the age of two. These guidelines are revised every five years by a committee, the Dietary Guidelines Advisory Committee, appointed by the Secretary of the U.S. Department of Health and Human Services and the Secretary of the U.S. Department of Agriculture.

Recommendations for weight management from the Dietary Guidelines, suggest Americans "maintain body weight in a healthy range and balance calories from foods and beverages with calories expended" (USDHHS/USDA, 2005). According to the Dietary Guidelines for Americans, the population of overweight children should "reduce the rate of body weight gain while allowing growth and development" (2005).

The following are key recommendations based on a 2,000 calorie diet from the Dietary Guidelines for Americans:

- 2 cups of fruit daily

- $2 \frac{1}{2}$ cups of vegetables daily

- 6 ounce-equivalents grains or grain products, with at least half (3 ounces) as whole grains

- 3 cups of reduced- or low-fat dairy daily

- Limit intake of fats and oils high in saturated and/or trans fatty acids, and choose products low in such fats and oils

- Choose and prepare foods and beverages with little added sugars or caloric sweeteners (USDHHS/USDA, 2005)

- Discretionary Calorie Allowance is less than 300 calories ( 267 calories) 
The expert committee on the assessment, prevention, and treatment of child and adolescent overweight and obesity was convened in 2005 by the American Medical Association (AMA), in collaboration with the Department of Health and Human Services' Health Resources and Services Administration (HRSA) and the Centers for Disease Control and Prevention (CDC) (Washington, 2008). This committee created and released 22 recommendations for health professionals providing obesity care. These recommendations include limiting consumption of sugar-sweetened beverages, encouraging consumption of diets with recommended quantities of fruits and vegetables, encouraging family meals in which parents and children eat together, and limiting portion sizes. These recommendations are in accordance with key recommendations from the 2005 Dietary Guidelines for Americans (USDHHS/USDA, 2005; Washington, 2008).

Proper, balanced nutrition is essential to good health and appropriate growth and development in children and adolescents (USDHHS/USDA, 2005). It is recommended to choose nutrient-dense foods over energy-dense foods. Nutrient-dense foods are foods that provide a considerable amount of vitamins and minerals, while not providing an abundance of calories. Nutrient-poor foods are the opposite of nutrient-dense, they provide few, if any, vitamins and minerals, while providing calories. Nutrient-poor foods are also commonly referred to as empty-calorie foods. To control calorie intake and body weight, it is important to decrease the intake of nutrient-poor foods when increasing one's intake of nutrient-dense foods such as fruits, vegetables, low-fat dairy and whole grains. Roseman, Yeung, and Nickelsen (2007) note that consumption of energy-dense foods, high dietary fat content, high consumption of sugar-sweetened beverages and high-sugar 
foods, and low fruit and vegetable consumption are dietary factors related to excess weight in children.

\section{Physical Activity and the Neighborhood}

Household income has been shown to impact a child or adolescent's risk for obesity (Singh et al., 2007; Spear et al., 2007). The lower socioeconomic status neighborhoods tend to be populated by more minorities and have decreased access to facilities promoting physical activity and healthful eating (Spear et al., 2007). Higher income neighborhoods tend to have more resources (supermarkets, parks, recreational facilities, etc.) than lower income neighborhoods do. The closer resources such as parks, recreation facilities, and/or bike/pedestrian trails are to a neighborhood, the more likely people are to utilize those resources (Booth et al., 2005). In some lower socioeconomic status communities, safety issues such as high traffic and high crime limit a child's ability to play and be active outside of the house. Limited ability to be physically active decreases an individual's daily energy expenditure and therefore, increases the individual's risk for overweight or obesity. In addition, schools found in lower socioeconomic status areas, are unable to maintain quality physical education programs (Spear et al., 2007). Less total physical activity throughout the day leads to an increased prevalence of childhood and adolescent overweight. Lower socioeconomic status area schools lack the money to fund not only physical education programs, including team sports, but also lack funding for programs promoting healthful eating and lifestyle habits.

Supermarket concentration and convenient store concentration can vary markedly in high versus low socioeconomic status communities (Booth et al., 2005). Supermarkets and farmers' markets are found in greater density in high socioeconomic status 
neighborhood communities, while convenience stores, specialty food markets, and small grocery stores are found in greater density in lower socioeconomic status neighborhood communities. Supermarkets have been identified as having a wider variety of fresh produce and more healthful food items, when compared to small grocery stores or convenient stores, which help facilitate healthful eating habits.

Fast-food restaurants were more likely to be found in middle to low socioeconomic status communities than in a higher socioeconomic status community where sit-down style restaurants were found to be more common. Consumption of fast food has increased along with the portion sizes at fast food restaurants (Demory-Luce, 2005). The trend of increased consumption and portion size are seen with the trend of increasing weight in American children and adults. These coinciding trends suggest a possible relationship between fast food consumption and overweight.

\section{Treatments of Child and Adolescent Overweight}

Child and adolescent overweight, as a current public health concern, has many government officials and agencies, local communities and schools, and medical professionals seeking change. The goal of treatment is to lose weight safely, maintain current weight, or at the very least to prevent additional fat gain. A variety of programs have been designed to improve lifestyle behaviors (diet and physical activity practices) through multi-component treatments combined with a follow-up plan (ADA, 2006).

\section{Individual- and Family-Based Treatment}

Family-based treatments are organized in a group-setting with family participation, while individual-based treatments are one-on-one counseling sessions (ADA, 2006). Multi-component family-based treatments involving nutrition counseling, 
encouraging physical activity, lifestyle modification, and some type of follow-up component(s), appear to be more effective than individual-based programs due to the additional support and accountability received during and after the treatment intervention. Parent training and involvement in nutrition and lifestyle counseling also appears to positively affect the long-term success of treatment.

Limitations of family-based treatment include lack of parental time and lack of parental motivation, both of which can greatly affect the success of the child. Unequivocal research to support or oppose individual-based treatment is currently not available in the literature, suggesting future research conducting and evaluating treatment(s) of this kind (ADA, 2006).

\section{School-Based Treatment}

School-based treatments are typically multi-component treatments implemented in one or more schools. School-based treatment has the potential to reach a number of children (ADA, 2006). Treatment can easily be incorporated into the curriculum (physical education class, health class) and potentially the child's free time (recess). Lunch time can also be included in the treatment as a way to model and re-enforce healthy dietary habits. It is important to use the program as a treatment for overweight children and prevention of overweight for normal-weight children to avoid additional psychosocial complications by singling out overweight children for the treatment. Choosing only overweight students to participate in the treatment may cause the children to feel isolated, embarrassed, or stigmatized by the normal weight students. Healthy lifestyle behaviors such as regular physical activity and healthy eating should be 
promoted and modeled to all students, regardless of weight status. Multi-component school-based treatment is recommended by the American Dietetic Association (2006). Community-Based Treatment

Community-based treatments are multi-component treatments initiated by a group within the community aimed at promoting well-being for the community at large (excluding schools) through policy change and social marketing. Currently available literature lacks substantial information regarding community-based treatment of obesity in children or adolescents (ADA, 2006). Community-based treatment has the potential to reach the largest number of children and adolescents, and therefore has the greatest potential to positively affect their lifestyle behaviors. According to the American Dietetic Association (2006), several such studies are in progress, but the final results have not yet been released. The current lack of sufficient data on this style of treatment suggests the need for further research in the field. The complexity of the problem and individuality of the potential subject population presents the opportunity for a variety of studies to help determine the most effective methods to combat this public health crisis.

O'Connor et al. (2008) conducted a community-based weight management program for overweight 13-16 year-old Australian adolescents. The study's participants were involved in seven semi-structured group sessions over the five-month period, focusing on increasing physical activity, making healthy eating choices, and improving self-esteem. The results of this study report significant improvements in waist circumference $(\mathrm{P}<0.0001)$, adolescent self-perception of physical appearance $(\mathrm{P}<0.048)$ and adolescent self-perception of romantic appeal $(\mathrm{P}<0.041)$. Fear of stigmatization by peers lead the adolescents in this study to refuse participation in a school-based treatment 
program. The results of this study suggest community-based treatment with follow-up measures is an effective weight management treatment.

Residential weight-loss camps can be an effective form of community-based treatment. Current available research in this area is limited, but the existing literature is promising. Gately et al. (2005) reported significant reductions $(\mathrm{P}<0.05)$ in BMI score, weight, and fat mass in 185 overweight children (mean age 13.9 years) enrolled in a residential summer weight-loss camp. Significant improvements $(\mathrm{P}<0.05)$ in the campers' self-esteem and aerobic fitness were also observed. In a separate study, a highly significant decrease $(\mathrm{P}=0.000)$ in body mass was reported for 194 overweight children (mean age 12.6 years) enrolled in a residential summer weight-loss camp in Massachusetts (Gately et al., 2000). The improvements seen in the campers' condition(s) appear to be related to the amount of time spent at camp. Eighty percent of campers reduced their BMI by at least one BMI unit in an approximately four week stay at camp (Gately et al., 2005). The longer the camper stays at camp, the greater benefits (i.e. weight lost, BMI score, aerobic fitness).

Parents play an essential part in influencing their child's eating habits (NeumarkSztainer et al., 2003). In separate studies Epstein (1996) and Epstein et al. (1998) found greater success with family-based weight reduction interventions that targeted both parents and children. Family-based weight reduction interventions reporting the greatest success emphasize realistic and coordinated goals for parent(s) and child and include strategies to facilitate behavior modification, positive reinforcement, and increase problem solving abilities (Golan and Crow, 2004). Parent training and involvement in nutrition and lifestyle counseling also appears to positively affect the long-term success 
of treatment (ADA, 2006). Research suggests this intervention should be conducted as a multi-component family-based weight loss intervention to achieve the greatest outcomes possible. 


\section{STATEMENT OF THE PROBLEM}

Childhood and adolescent overweight/obesity has become a major public health concern in recent years. The prevalence of overweight in our nation's youth has been increasing at an alarming speed, with no signs of stopping. The state of West Virginia is ranked among the states with the highest prevalence of childhood and adolescent overweight. Childhood and adolescent overweight is associated with physical, mental, and emotional complications some complications can be classified as co-morbidities (i.e. type 2 diabetes mellitus, dyslipidemia, hypertension, sleep apnea).

Concerns for healthcare costs accompany the public's concern for the health of the nation's youth. As the number of overweight children and adolescents continues to grow, the medical attention this population requires will increase. More medical attention creates higher medical bills. These complications do not end with adolescence though, complications associated with obesity continue (and can potentially magnify) in adulthood, once again potentially increasing the cost of the population's healthcare. Monetary consequences of overweight and obesity carry into the work place as loss of productivity and wages due to absenteeism.

An epidemic such as this has many potential causes. One potential cause may be that children have less opportunity to play and to be active in their neighborhoods due to safety concerns. Another potential cause is that children are consuming too many energydense foods and not enough nutrient-dense foods. Soda and other sweetened beverages are replacing milk throughout the day and high sugar, high fat foods are replacing fruits and vegetables in the diets of today youth. Consuming energy-dense or empty-calorie foods instead of nutrient-dense foods, increases daily calorie consumption and may 
contribute to weight gain. Education should be provided to youth and their parents about the importance of consuming a well-balanced diet filled with nutrient-dense foods.

\section{HYPOTHESIS}

A two-week residential weight-loss camp is an effective treatment to teach skills that will promote healthier eating behaviors to 10 through 14 year old adolescents living in West Virginia. This treatment will result in the camp participants reporting an increased number of eating occasions that include fruits, vegetables, low-fat dairy, and whole grains daily and decrease the number of eating occasions that include highly sweetened drinks and high sugar/ high fat foods.

\section{Specific Aims}

- Increase the number of eating occasions camp participants choose to consume fruits, vegetables, low-fat dairy and whole grains throughout the day.

- Decrease the number of eating occasions camp participants choose to consume highly sweetened drinks (i.e. soda) and high sugar/ high fat foods throughout the day. 


\section{CHAPTER 3}

\section{OBJECTIVES OF THE STUDY}

\section{Subjects}

Subjects are overweight children and adolescents age 10 through 14 years as of July 1,2008 . Subjects were recruited to participate in a two-week residential lifestyle modification camp with three weekend follow-up sessions over the course of a year. To be eligible to attend the camp, a subject must have been of appropriate age as of July 1 , 2008; provide a referral from their physician; have a BMI score at, or above, the $85^{\text {th }}$ percentile on the CDC growth charts (Appendix 1 and 2); complete an application contract for subject and at least one parent or legal guardian; and have the ability to participate in all camp activities. The subjects were recruited through schools, physicians' offices, community centers, newsprint ads, and various other venues to participate in this pilot camp. The target subject number was 26, with 13 boys and 13 girls. Research protocols were approved by the institutional review board at West Virginia University IRB on file (H-20994).

\section{Intervention}

This program is a multidisciplinary family-based intervention for overweight or at-risk-for-overweight children aged 10 through 14 years. The intervention consisted of a two-week residential weight-loss camp held on a college campus (West Virginia University), as well as three follow up weekends held at different locations throughout the state.

During the initial two-week camp session, the children participated in four formal 50-minute nutrition education lessons. One nutrition lesson was presented through a 
computer program titled Take Charge, Be Healthy. Take Charge, Be Healthy consists of electronic-modules discussing different aspects of well-being including physical activity, nutrition, and overall health. The subjects completed a pre- and post- nutrition knowledge quiz as part of the Take Charge, Be Healthy curriculum (Appendix 3). The quiz was administered via the electronic-module in one 50 minute session, and was independent of future nutrition education lessons. The remaining three nutrition lessons were taught by six West Virginia University dietetic interns, two teaching at a time. The lessons taught by the WVU interns focused on the Plate Method (Appendix 4) and 'Always' food choices vs. 'Sometimes' or 'Sparing' food choices. The interns collaborated with one another to designate topics that were taught to the subjects, with each pair of interns developing their individual lesson. The first lesson focused on the basics of the Portion Plate Method (Appendix 5). The second lesson taught to the campers concentrated on energy balance and nutrition (Appendix 6). The final lesson taught to the subjects by WVU interns focused on how to read and use food labels (Appendix 7).

Additional nutrition education was provided to the subjects outside of the formal nutrition lessons. A chef gave a cooking demonstration for the campers after dinner one evening, showcasing healthy recipes ideas. The subjects were able to sample the dishes made by the chef and interact with him once the demonstration was complete. The goal of the chef's presentation was to showcase how easy it can be to make delicious, healthy dishes with simple and fresh ingredients. Subjects also helped prepare a morning snack for themselves in the WVU Foods Laboratory six times throughout the camp session. By helping to prepare some of their own snacks, it was hoped that subjects' self-efficacy to prepare healthy snacks at home would improve, as would the likelihood that subjects will 
prepare these types of healthy snacks for themselves at home. This also provided the opportunity for subjects' to apply some of the knowledge they had gained through prior nutrition education lessons.

The subjects planned and prepared a healthy dinner menu, including dessert, with the help of WVU dietetic interns and camp staff. The dinner was in honor of the subjects and their families for committing to healthy lifestyle changes. The subjects were also responsible for purchasing the food needed to prepare the dinner at a local grocery store. The subjects received help grocery shopping for the dinner from four dietetic interns; while at the grocery store the dietetic interns taught the subjects about nutrition through a grocery store tour (Appendix 8). The four dietetic interns and camp staff also helped the subjects prepare the meal for their families. The dietetic interns and camp staff were responsible for portioning and serving the food to subjects and their families.

Throughout the two-week residential camp, subjects were fed buffet-style in a college-dormitory cafeteria. Healthy options such as fresh fruits, a salad bar, whole grain breads, and lean deli meats were available to the subjects daily. However, fried foods, indulgent desserts, soda fountains, and other high sugar/high fat options were also available daily. Due to the availability of some less-than-healthy choices, meal times were used for applied nutrition education with the subjects. Camp staff was expected to model healthy food choices, moderation, and discuss the healthy choices available in the cafeteria with the subjects during meals. Subjects were also encouraged to taste a variety of healthy foods or dishes they may have been unfamiliar with at the start of camp. Healthy nutrition selections made by the subjects were publically acknowledged and praised, as to positively reinforce the behavior. Poor nutrition selections made by subjects 
were only briefly recognized and discussed privately between the camper and camp staff during the meal. In addition, one evening during camp, subjects designed and made their own versions of the Portion Plate (Appendix 4) at a local paint-your-own-pottery establishment, The WOW! Factory. The subjects were able to take these plates home when camp ended to help reinforce the portion plate method.

Camp staff provided lifestyle coaching for subjects and their families as a part of the interventions follow-up component. Each member of the camp staff was assigned to provide lifestyle coaching, via telephone calls, mail, or internet correspondence, to specific subjects and their families for 12 months following the two-week camp intervention. The lifestyle coaching aspect of the intervention provided a personal contact to the subjects and their families. Camp staff monitored the progress subjects and their families were making and were able to offer suggestions on how to overcome barriers the families were facing. Lifestyle coaching was included in the overall intervention to continue provide additional support to families while they work towards making healthy lifestyle behaviors into habits.

The multi-faceted nutritional education component of the camp was designed to help the subjects and their families make healthier food choices and learn the benefits of a well-balanced diet. The WVU dietetic intern pairs, along with the camp staff, also modeled healthy food choices to the subjects by joining the subjects for lunch immediately following the presentation of their lessons. Through hands-on learning experiences, modeling, and an increased awareness of healthful eating options, it was hoped that campers would start assembling the foundation for life-long healthy eating habits. 


\section{Data Collection}

Subjects were asked to keep a three-day diet journal prior to arriving at the twoweek camp intervention (July 2008). This was repeated prior to the first weekend followup session, which was three months after the initial two-week camp session (October 2008). The three-day diet journals were collected from each subject and their family during check-in activities on both time occasions. Diet quality of the subjects was evaluated using the three-day diet journal records from both time occasions. The threeday diet journal was evaluated for increased consumption of healthful foods (i.e. fruits, vegetables, whole grains, low-fat dairy, and water) and decreased consumption of empty calorie foods (i.e. fried foods, sugar sweetened drinks, candy, etc.). Data from the Take Charge, Be Healthy computer education program was compiled and accessed through the computer software itself.

\section{Measurements}

Measurements were assessed by the above mentioned three-day diet journals. Written instructions on how to keep a three-day diet journal (Appendix 9) were mailed to the subjects and their families prior to the initial two-week camp session and prior to the follow-up weekend session. No additional instruction(s) or examples on completing a three-day diet journal were provided to the subjects and their families, nor were the threeday diet journals reviewed for accuracy with the subjects upon measurement collection on either time occasion. It appears several subjects did not seek help (from a parent, grandparent, older sibling) when recording their three-day diet journals, and some of the subjects' ability to comprehend and follow the instructions provided may have been limited. 


\section{Program Development}

Camp NEW You is a pilot program that was designed to help youth (10 through 14 years of age) and their parents identify and implement lifestyle changes. The lifestyle changes focused on promoting balanced nutrition and increasing physical activity. This pilot camp's programming aimed to help set and abide to appropriate goals, empower campers to make their own healthy decisions, and emphasize the importance of the parent participation in healthy behavior change through parent education. Camp NEW You is unique in that (1) it was developed and organized by an interdisciplinary advisory board, (2) it focuses on behavior change through self-efficacy, behavioral skills, behavioral capacity, and social networking, (3) it consists of a two-week summer residency program with a variety of educational experiences for children and parents, and (4) it has a structured 12-month follow-up intervention designed to provide continued support for families as the targeted behavior change become habitual (periodic weekend retreats, regular telephone coaching, personal accountability mechanisms).

Figure 1.

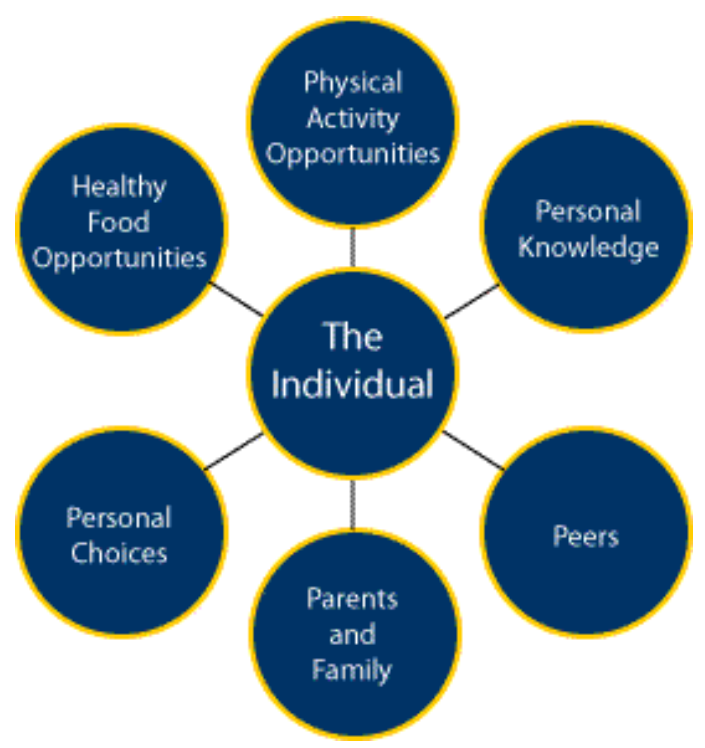




\section{Funding}

Due to the financial demands of an intervention this large, and to ensure that this intervention will be accessible to all families in West Virginia, financial assistance was available for subjects and their families. According to the U.S. Census Bureau (2006), in regards to personal income per capita, West Virginia is trailed only by Mississippi and Arkansas. West Virginia Public Employees Insurance Agency (PEIA), the Children's Health Insurance Program (CHIP), Mountain State Blue Cross/Blue Shield and WVU Health Plan insurance providers covered the camp's attendance fee for those subjects who qualified. Camp NEW You also provided financial scholarships to eleven additional subjects, enabling these subjects to attend at the two-week camp session and the three follow-up weekend sessions. Additional financial consideration for the camp program was provided by the Claude Worthington Benedum Foundation, The West Virginia Office of Healthy Lifestyles (OHL), and the Mylan Charitable Foundation.

\section{Data Analysis}

Only subjects with recorded pre- and post-camp diet journals were used in the data analysis. Each subject's diet journal was independently analyzed and recorded by the same researcher. Each diet journal was analyzed to report the number of times each subject reported consuming a low-fat dairy product, fruit, vegetable, whole grain, soda or sweetened beverage, water, and/or a high sugar/ high fat food item during the day. Lowfat dairy products were defined as dairy products in which the fat content has been reduced; this includes products such as reduced fat and non-fat milks, low-fat or non-fat yogurts, reduced fat cheese, etc. Fruits and vegetables are defined as whole fruits or vegetables and fruits and vegetables with minimal processing and additives. Fresh, 
canned or frozen fruits and vegetables, dried fruits, applesauce, etc. were counted as an eating occasion containing a fruit or vegetable. Whole grains are products made from all the essential parts and naturally-occurring nutrients of the entire grain seed. Whole grain products include any product labeled $100 \%$ whole grain, any product made primary of a whole grain (oatmeal, whole wheat, etc.), popcorn, brown rice, and others. Soda and sweetened beverages included regular soda(s) and any drink sweetened or flavored with caloric sweeteners such as fruit punch or sweet tea. Beverages sweetened with a noncaloric sweetener, such as aspartame or saccharin, did not count in the sweetened drink or water category. High sugar/fat foods are defined as foods with high amounts of added sugars, such as baked goods or candies, or high amounts of fat, such as fried chicken or potato chips.

Once the researcher analyzed and recorded each subject's diet, this record was complete. The researcher then calculated the three-day average for each of the categories above, respectively. The calculated three-day average, for each time occasion, was analyzed using a matched pairs T-test in the Statistical Analysis Software (SAS) program to determine significance and treatment effectiveness. The Take Charge, Be Healthy preand post-nutrition knowledge quiz results were also analyzed using a matched pairs Ttest. 


\section{CHAPTER 4}

\section{RESULTS}

Results from the Take Charge, Be Healthy pre- and post- nutrition knowledge quiz showed a significant increase in the subjects' nutritional knowledge (Table 2). Subjects answered less than $50 \%$ of the nutrition quiz questions correctly prior to completing the Take Charge, Be Healthy nutrition module, but were able to answer $68.6 \%$ of the nutrition quiz questions correctly after completing the module. All subjects were required to complete the Take Charge, Be Healthy electronic education sessions throughout their two-week stay at camp. Camp NEW You started with 24 subjects. At the time this nutrition education was administered, one subject had dropped out of the intervention due to homesickness.

Table 2. Take Charge, Be Healthy Pre- Post- Knowledge Nutrition Quiz Results

\begin{tabular}{|l|c|c|c|c|c|}
\hline & N & Mean \pm SD & t & df & Sig. (2-tailed) \\
\hline $\begin{array}{l}\text { \% Correct } \\
\text { Pre-Quiz }\end{array}$ & 23 & $44.928 \pm 170561$ & -5.210 & 22 & .000 \\
\hline $\begin{array}{l}\text { \% Correct } \\
\text { Post-Quiz }\end{array}$ & 23 & $68.599 \pm 16.634$ & & & \\
\hline
\end{tabular}

Pre- and post- diet journal information measurement collection provided a three month perspective of the population. Of the 24 original subjects, 22 completed the initial two-week camp session. Of these 22 subjects who completed the initial camp session, 17 completed pre-camp diet journals, 11 completed post-camp diet journals three-months after camp, and 10 subjects completed both pre-camp and post-camp diet journals. Only the results of subjects $(N=10)$ with recorded pre- and post-camp diet journals are reported here. 
Diet records prior to camp indicated that on average subjects were not meeting recommendations for servings of fruits, vegetables, low-fat dairy, or whole grains, and were exceeding recommendations for soda/sweetened drinks and high fat/sugar foods, based on a 2,000 calorie diet (Table 3). Soda/ sweetened drinks and high fat/sugar foods are considered discretionary calories. Discretionary calories based on a 2,000 calorie per day diet should not be consumed in greater amounts than 267 calories daily (USDHHS/USDA, 2005).

Table 3. Subjects' Pre-camp Recorded Average Dietary Intake

\begin{tabular}{|l|c|c|}
\hline \multicolumn{1}{|c|}{ Food Item } & $\begin{array}{c}\text { Subjects' Average } \\
\text { Daily Intake }\end{array}$ & Daily Recommendation* \\
\hline Fruit & 0.566 & 4 servings \\
\hline High Sugar/Fat Food & 5.300 & Limit \\
\hline Low-Fat Dairy & 0.833 & 3 servings \\
\hline Soda/Sweetened Drink & 2.500 & Limit \\
\hline Vegetable & 0.600 & 5 servings \\
\hline Water & 0.835 & 8 servings \\
\hline Whole Grain & 0.366 & At least 3 servings \\
\hline
\end{tabular}

*Based on a 2,000 Calorie Diet $\mathrm{N}=10$

Diet records collected during the first follow-up weekend in October, three months postintervention, revealed that on average, subjects have increased servings of fruits, low-fat dairy, vegetables, and whole grains. Diet records from post-intervention also revealed that subjects are consuming a decreased number of servings of soda/sweetened drinks and high sugar/fat foods. No difference was noted in subjects' water consumption (Table 4). 
Table 4. Subjects' Pre- and Post-camp Recorded Average Dietary Intake

\begin{tabular}{|l|c|c|c|}
\hline \multicolumn{1}{|c|}{ Food Item } & $\begin{array}{c}\text { Subjects' Average } \\
\text { Daily Intake } \\
\text { Pre-Camp }\end{array}$ & $\begin{array}{c}\text { Subjects' Average } \\
\text { Daily Intake } \\
\text { Post-Camp }\end{array}$ & $\begin{array}{c}\text { Daily } \\
\text { Recommendation* }\end{array}$ \\
\hline Fruit & 0.566 & $1.066^{* *}$ & 4 servings \\
\hline High Sugar/Fat Food & 5.300 & 4.535 & Limit \\
\hline Low-Fat Dairy & 0.833 & 1.166 & Limit \\
\hline $\begin{array}{l}\text { Soda/Sweetened } \\
\text { Drink }\end{array}$ & 2.500 & $1.433 * *$ & 5 servings \\
\hline Vegetable & 0.600 & 0.966 & 8 servings \\
\hline Water & 0.835 & 0.867 & At least 3 servings \\
\hline Whole Grain & 0.366 & 0.599 &
\end{tabular}

*Based on a 2,000 Calorie Diet.

** Significance $(\mathrm{P}<0.05)$

$\mathrm{N}=10$

The subjects significantly increased $(\mathrm{P}<0.02)$ the number of times they reported eating a fruit throughout the day and significantly decreased $(\mathrm{P}<0.02)$ the number of times they reported consuming a soda or other sweetened beverage throughout the day (Table 4). No other variables proved to be significant after analysis was complete. However, slight increases in servings of low-fat dairy, vegetables, and whole grains were observed, as well as numerical decreases in servings of high sugar/fat foods. 


\section{CHAPTER 5}

\section{DISCUSSION}

This intervention was designed to assist children and parents in West Virginia adopt healthy lifestyle behaviors that could potentially lead to weight-loss, through improved nutrition choices. This intervention highlights the importance of decisionmaking and goal setting (while also emphasizing the role parents play in helping to provide a home setting) with opportunities for engaging in healthy lifestyle behaviors.

Based on initial evaluation of Camp NEW You's subject nutrition education component, it appears the intervention was effective in increasing the health awareness of subjects' and their families. Subjects' and their families were educated on how to make nutritious decisions at meal times and snack times. The data from this intervention should be compared with data from a follow-up study to monitor the growth patterns and weight classifications of the target population. Subjects served as their own control for this intervention study. These results do, however, provide base-line measurements and information for the continuation of a multi-component family-based lifestyle modification program to monitor the growth of the target population.

The subjects were initially introduced to the nutrition education component of this intervention through the Take Charge, Be Healthy computer education program. Twentythree subjects completed a pre- and post- nutrition knowledge quiz. Results from the Take Charge, Be Healthy pre- and post- nutrition knowledge quiz showed a significant increase in the subjects' nutritional knowledge. After completing the Take Charge, Be Healthy nutrition knowledge module, subjects were able to correctly answer a higher percentage of quiz questions (68.6\%) versus before completing the module (44.9\%). 
These results suggest significant improvement in the amount of nutrition knowledge the subjects gained from the nutrition education module and the knowledge subjects were able to translate into applied knowledge.

The first nutrition lesson presented by the WVU dietetic interns sparked the subjects' interest in nutrition and the role(s) it plays in health. After the nutrition lesson focusing on the Portion Plate (Appendix 5) was delivered on the first Thursday of the initial two-week camp session (Appendix 10), the subjects began asking the camp staff to examine the subjects' plates/choices to ensure their acceptability. Because of this, a "Best Plate of the Day" Award was created and given to one subject per day at the end of dinner for the remainder of camp. Once formal nutrition education began with the subjects, the subjects were more open to trying new foods and/or familiar foods with a new twist. Subjects began asking for help mixing vinegar and oil(s) for salad dressings, requesting help to prepare healthy mealtime sandwiches, and inviting suggestions on how to prepare satisfying balanced meals, etc. When the subjects' families came to participate in the two-week camp session's closing weekend events, several subjects were judging their family members plates and even offering suggestions to their family members on how to improve their choices.

The applied nutrition education pieces were also vital to increasing the subjects' overall knowledge of nutrition. The subjects were extremely interested in the chef's cooking demonstration and learning some of his tricks for healthy meal preparation. The subjects interacted well with the chef and had several questions during and after the chef's demonstration. The subjects prepared six different morning snacks for themselves throughout their two-week stay at camp (Appendix 10 and 11). By having the subjects 
prepare a variety of healthy snacks for themselves, with guidance from persons from the WVU Human Nutrition and Foods Department and camp staff, the subjects' self-efficacy for preparing healthy snacks improved. Improving a subject's self-efficacy to prepare healthy snacks increases the chances that a subject will choose and prepare healthy snacks for themselves in the future.

Subjects planned and prepared a healthy dinner menu with the guidance of the WVU dietetic interns and the camp staff. While shopping for the menu's ingredients, WVU interns presented the subjects with a tour of the grocery store (Appendix 8). This tour included strategies and tips on how to successfully choose healthy options during a trip to the grocery store. The meal was prepared by subjects, camp staff, and WVU dietetic interns in the WVU Food Laboratory. Meal preparation time was used, not only to prepare the dinner meal, but also to teach healthy cooking methods and basic kitchen skills the subjects can continue to utilize throughout life and improve self-efficacy in these areas. The meal was well received by subjects' and their families. A cookbook with all the recipes from the family dinner and self-snack preparation was created and given to the subjects' families at the end of the two-week camp session (Appendix 11).

As a result of all the nutrition education subjects received throughout the twoweek camp session, subjects significantly improved their average daily fruit intake and significantly decreased their average daily soda/ sweetened beverage intake. These results are especially important because increased fruit [and vegetable] consumption is associated with weight reduction/maintenance (Rolls et al., 2004). Soda intake often displaces milk and water intake and is negatively associated with weight (Nielsen and Popkin, 2004). Improving the diet in these two areas could help subjects to achieve a 
healthy weight classification. However, even with these significant improvements, subjects are still not meeting the recommendations outlined in the 2005 Dietary Guidelines for Americans (USDHHS/USDA, 2005). A difference in water consumption was not observed with this intervention, but the subjects' post-camp three day diet journals suggest subjects are consuming more beverages sweetened with non-caloric sweeteners and fewer beverages sweetened with caloric-sweeteners. Beverages sweetened with non-caloric or artificial sweeteners did not count as an eating occasion with water or a soda/sweetened beverage. Subjects and their families should continue to be educated about the importance of consuming adequate servings of healthful foods (i.e. fruits, vegetables, low-fat dairy, and whole grains) and limiting servings of empty-calorie foods (i.e. soda/sweetened beverages and high sugar/fat foods) on a daily basis. Subjects and their families should also continue to be encouraged to increase servings of healthful foods and limit servings of empty-calorie foods daily.

The multi-faceted nutritional education component of the camp intervention has helped the subjects improve their knowledge of nutrition, make overall healthier food choices and learn the benefits of consuming a well-balanced diet. Through hands-on learning experiences, modeling, and an increased awareness of healthful eating options, campers have began to assemble the foundation for life-long healthy eating habits through their time at Camp NEW You.

Future research should include more extensive, detailed evaluation of the subjects' and their families' diets through three-day diet journals. Subjects' and their families' three-day diet journals should be compared to determine change(s) that occurred within the family unit. Subjects' meals should also be served in a more 
controlled eating environment throughout the initial two-week camp session. Subjects ate without restriction in a buffet-style, college-dormitory cafeteria during the initial twoweek camp session. By providing the subjects with fewer options, at least initially, subjects would be forced to taste and try some healthy food items they might not normally choose. When considering future research of this nature, formal nutrition education lessons should be introduced to the subjects earlier in the initial two-week camp intervention. Nutrition education was not introduced to the subjects until day four of the two-week camp session. Therefore subjects were eating buffet-style without any nutrition instruction, three meals a day for four days. Valuable applied nutrition education opportunities were likely lost in the four days prior to the subjects' first formal nutrition education session. Long-term prospective studies and further engagement of subjects and their families is necessary to fully understand the effect of the nutrition education received through the initial two-week camp session on the newly adopted healthy lifestyle habits of this population. 


\section{CHAPTER 6}

\section{CONCLUSION}

Camp NEW You is an effective intervention for teaching subjects how to make nutritionally balanced decisions at meal and snack times. Using the Plate Method as a nutrition education tool throughout the initial two-week camp session is a successful way to help teach overweight adolescents to make healthier food choices during the day.

Results of this intervention provide base-line measurements and information for the continuation of a multi-component family-based lifestyle modification program to monitor the growth of the target population. The Dietary Guidelines for Americans (USDHHS/USDA, 2005) provided useful methodology for completing the assessment process and evaluating the effectiveness of Camp NEW You's nutrition education component. Obesity prevention and treatment interventions require the formation and sustainability of partnerships including the family unit, academia, and communities.

The short-term goals of the initial two-week residential camp intervention have been partially accomplished, in that significant improvement in fruit consumption and soda/ sweetened beverage intake was observed, and in the subjects' increased knowledge of nutrition. While statistically significant improvements were not observed in low-fat dairy, vegetable, whole grain, or high sugar/fat foods consumption, numerical improvements are noted. According to the post-camp three-day diet journals, subjects are closer to meeting the recommendations outlined in the 2005 Dietary Guidelines for Americans than they were prior to attending camp. The long-term goals of Camp NEW You is to establish lifestyle habits that will assist in promoting healthy body weight through increased good nutrition and physical activity. This goal can be achieved through 
continued support and participation for this multi-component family-based intervention by insurance providers in West Virginia; the WVU College of Physical Activity and Sports Sciences; the WVU School of Medicine (CARDIAC Project); the WVU College of Agriculture, Forestry and Consumer Sciences, WVU Extension Offices, and West Virginia families. The Camp NEW You intervention provides the foundation for the longitudinal study of this target population group. 


\section{LITURATURE CITED}

American Dietetic Association. 2006. Position Paper of the American Dietetic Association on Individual-, Family-, School-, and Community-Based Interventions for Pediatric Overweight. J Am Diet Assoc. 106:925-945.

Baker J L, Olsen L W, Sorensen T I A. 2007. Childhood body-mass index and the risk of coronary heart disease in adulthood. N Eng J Med. 357:2329-2337.

Behavioral Risk Factor Surveillance System Prevalence Data (BRFSS): Weight Classification Based on Body Mass Index (West Virginia). 2007. National Center for Chronic Disease Prevention and Health Promotion. [WWW Document] URL address: http://apps.nccd.cdc.gov/brfss/display.asp?cat=OB\&yr=2007\&qkey=440 $9 \&$ state $=\mathrm{WV}$

Bibbins-Domingo K, Coxson P, Pletcher M J, Lightwood J, Goldman L. 2007.Adolescent overweight and future adult coronary heart disease. $N$ Eng J Med. 357:2371-2379.

Booth K M, Pinkston M M, Carlos Poston W S. 2005. Obesity and the built environment. J Am Diet Assoc. 105:S110-S117.

Center for Disease Control and Prevention. United States Department of Health and Human Services. 2007. URL address: http://www.cdc.gov

Demory-Luce D. 2005.Fast food and children and adolescents: implications for practitioners. Clin Pediatr. 44:279-288.

Ebbeling C B, Pawlak D B, Ludwig D S. 2002. Childhood obesity: public health crisis, common sense cure. Lancet. 360:473-482

Epstein L H. 1996. Family based behavioral intervention for obese children. Int J Obes. 20:S14-S21.

Epstein L H, Myers M D, Raynor H A, Saelens B E. 1998. Treatment for pediatric obesity. Pediatrics. 101:554-570.

Finkelstein E A, Ruhm C J, Kosa K M. 2005. Economic costs and consequences of obesity. Annu Rev Pub Health. 26:239-257.

Freedman D S, Khan L K, Dietz W H, Srinivasan S R, Berenson G S. 2001. Relationship of childhood overweight to coronary heart disease risk factors in adulthood: the Bogalusa heart study. Pediatrics. 108:712-718.

Gately P J, Cooke C B, Barth J H, Bewick B M, Radley D, Hill A J. 2005. Children's residential weight-loss programs can work: a prospective cohort study of shortterm outcomes for overweight and obese children. Pediatrics. 116:73-77. 
Gately P J, Cooke C B, Butterly R J, Mackreth P, Carroll S. 2000. The effects of a children's summer camp programme on weight loss, with a 10 month follow-up. Intern J Obes. 24:1445-1452.

Golan M, Crow S. 2004. Parents are key players in the prevention and treatment of weight-related problems. Nutr Rev. 62:39-50.

Ludwig D S. 2007. Childhood obesity -the shape of things to come. $N$ Eng J Med 357:2325-2327.

National Center for Health Statistics. 2007. Health, United States, 2007 with Chartbook on Trends in the Health of Americans. Hyattsville, MD: US Department of Health and Human Services.

Neumark-Sztainer D, Wall M, Perry C, Story M. 2003. Correlates of fruit and vegetable intake among adolescents findings from Project EAT. Prev Med. 37:198-208.

Nielsen S J, Popkin B M. 2004. Changes in beverage intake between 1977 and 2001. Am J Prev Med. 27:205-210.

O’Connor J, Steinbeck K, Hill A, Booth M, Kohn M, Shah S, Baur L. 2008. Evaluation of a community-based weight management program for overweight and obese adolescents: The Loozit Study. Nutrition \& Dietetics. 65:121-127.

Rolls B J, Ello-Martin J, Carlton Tohill B. 2004. What can intervention studies tell us about the relationship between fruit and vegetable consumption and weight management? Nutr Rev. 62:1-17.

Roseman M G, Yeung W K, Nickelsen J. 2007. Examination of weight status and dietary behaviours of middle school students in Kentucky. J Am Diet Assoc. 107:11391145 .

Serdula M K, Ivery D, Coates R J, Freedman D S, Williamson D F, Byers T. 1993. Do obese children become obese adults? A review of the literature. Prev Med. 22:167-177.

Singh G K, Kogan M D, van Dyck P C. 2007. A multilevel analysis of state and regional disparities in childhood and adolescent obesity in the United States. J Comm Health.

Spear B A, Barlow S E, Ervin C, Ludwig D, Saelens B E, Schetzina K E, Taveras E M. 2007. Recommendations for treatment of child and adolescent overweight and obesity. Pediatrics. 120:S254-S288. 
Strong J P, Malcom G T, Newman W P III, Oalmann M C. 1992. Early lesion of atherosclerosis in childhood and youth: natural history and risk factors. J Am Coll Nutr. 11(suppl):51S-54S.

United States Census Bureau. (2006). Table 662, State Rankings- Statistical Abstract of the United States. United States Bureau of Economic Analysis. Washington DC: US Government Printing Office.

U.S. Department of Health and Human Services and U.S. Department of Agriculture. Dietary Guidelines for Americans, 2005. 6th Edition, Washington, DC: U.S. Government Printing Office.

Washington R. 2008. Overview of the expert committee's recommendations for prevention, diagnosis, and treatment of child and adolescent obesity. Progress Pediatr Cardio. 25:125-128.

Whitaker R C, Wright J A, Pepe M S, Seidel K D, Dietz W H. 1997. Predicting obesity in young adulthood from childhood and parental obesity. $N$ Eng J Med. 337:869873.

Wilcox P G, Weiner D S, Leighley B. 1988. Maturation factors in slipped capital femoral epiphysis. J Pediatr Orthop. 8:196-200. 
Appendix 1: 2000 CDC Growth Chart for Boys 2-20 years

2 to 20 years: Boys Stature-for-age and Weight-for-age percentiles

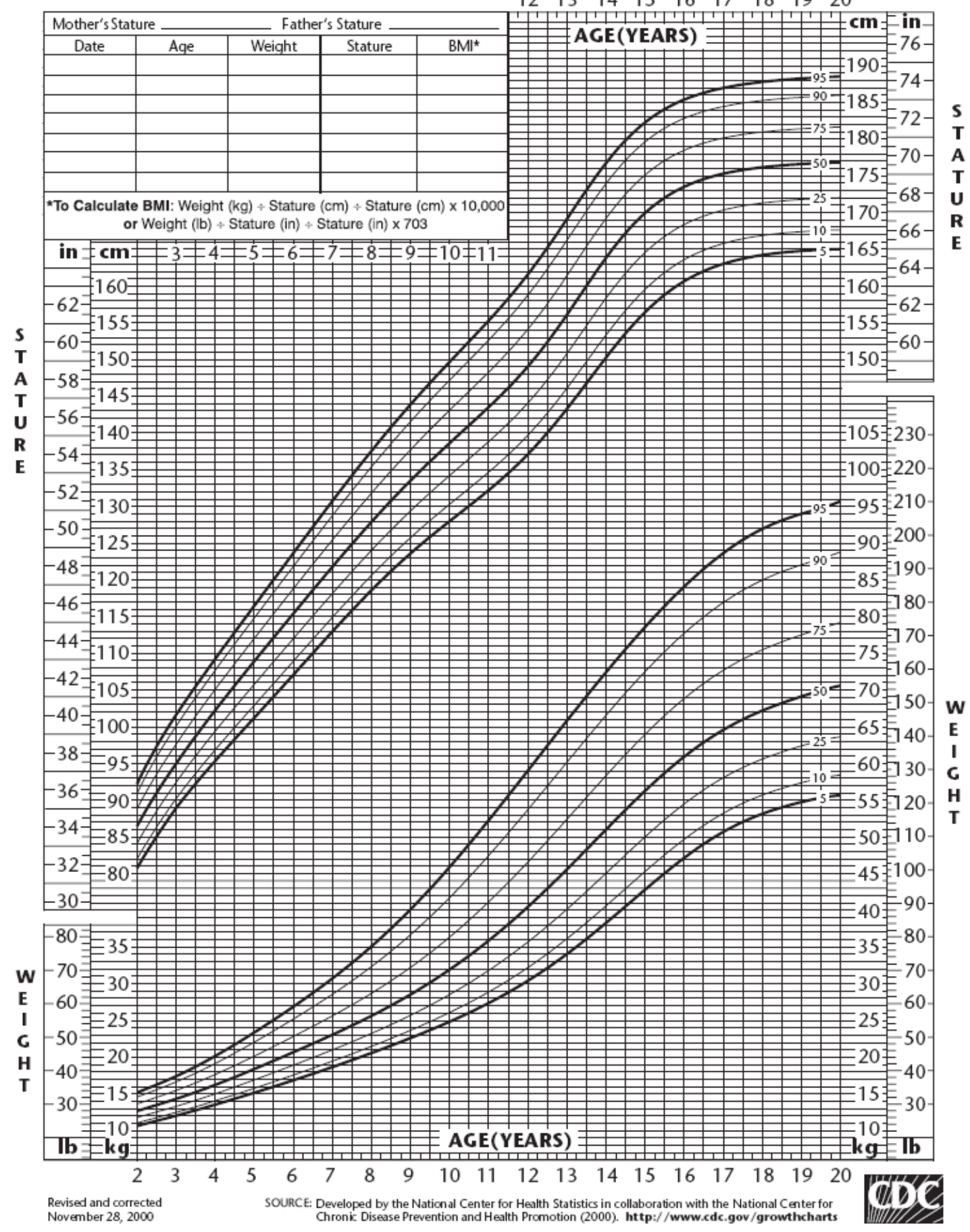

NAME

RECORD \#

$\begin{array}{lllllllll}12 & 13 & 14 & 15 & 16 & 17 & 18 & 19 & 20\end{array}$

\begin{tabular}{|c|c|c|c|c|}
\hline Mother's Stature & \multicolumn{4}{|c|}{ Father's Stature } \\
\hline Date & Aqe & Weight & Stature & BMI $^{*}$ \\
\hline & & & & \\
\hline & & & & \\
\hline & & & & \\
\hline & & & & \\
\hline & & & & \\
\hline & & & & \\
\hline
\end{tabular}

or Weight (b) $\div$ Stature (in) $\div$ Stature (in) $\times 703$ 
2 to 20 years: Boys Body mass index-for-age percentiles

NAME

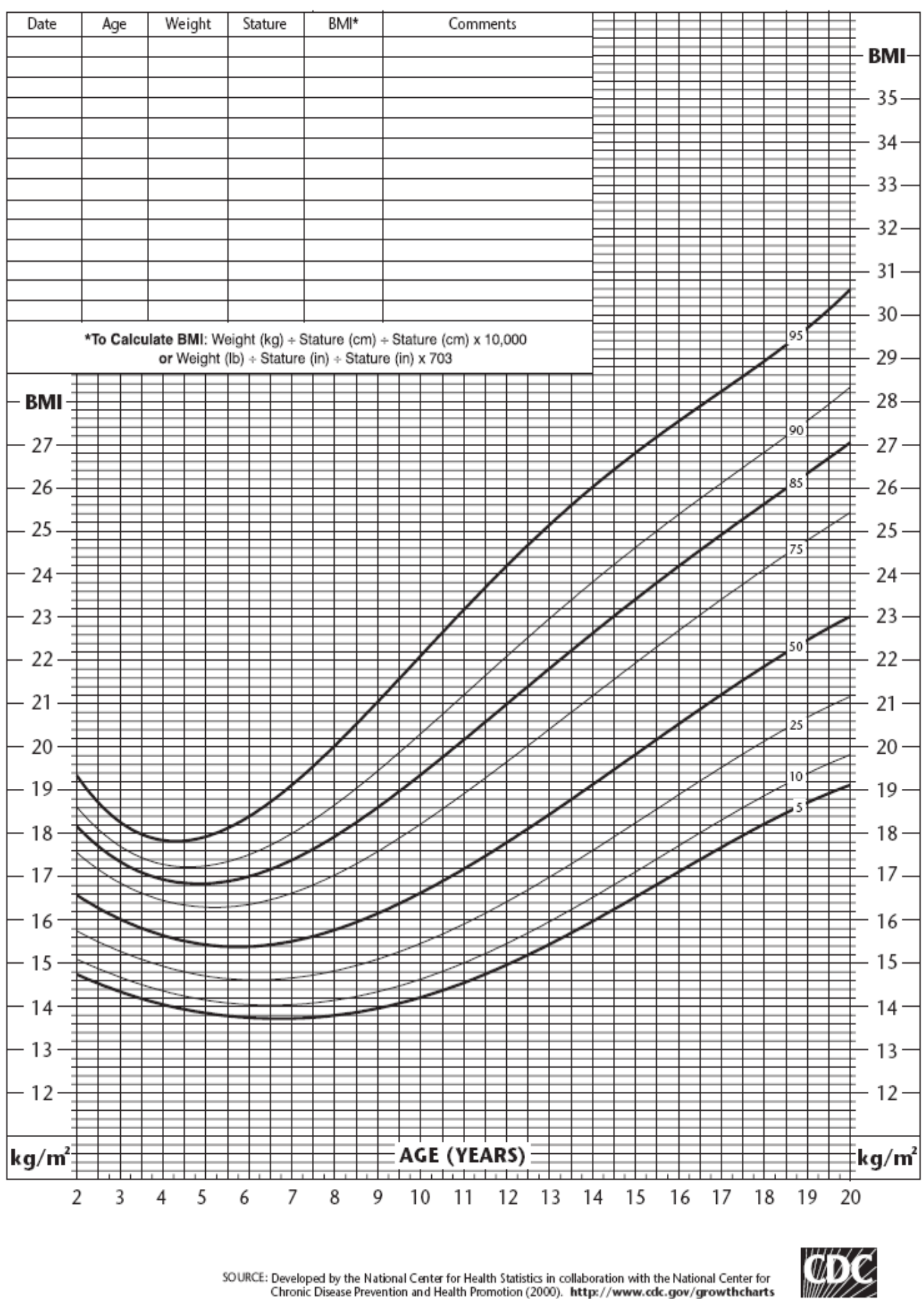


Appendix 2: 2000 CDC Growth Chart for Girls 2-20 years

\section{2 to 20 years: Girls Stature-for-age and Weight-for-age percentiles}

\begin{tabular}{|c|c|c|c|c|}
\hline Mother's Stature & \multicolumn{4}{c|}{ Father's Stature } \\
\hline Date & Ace & Weight & Stature & BMI$^{*}$ \\
\hline & & & & \\
\hline & & & & \\
\hline & & & & \\
\hline & & & & \\
\hline & & & & \\
\hline & & & & \\
\hline
\end{tabular}

*To Calculale BMI: Weight $(\mathrm{kg}) \div$ Stature $(\mathrm{cm}) \div$ Stature $(\mathrm{cm}) \times 10000$ or Waigh: (lb) $\div$ Stature (in) $\div$ Stature (in) $\times 703$

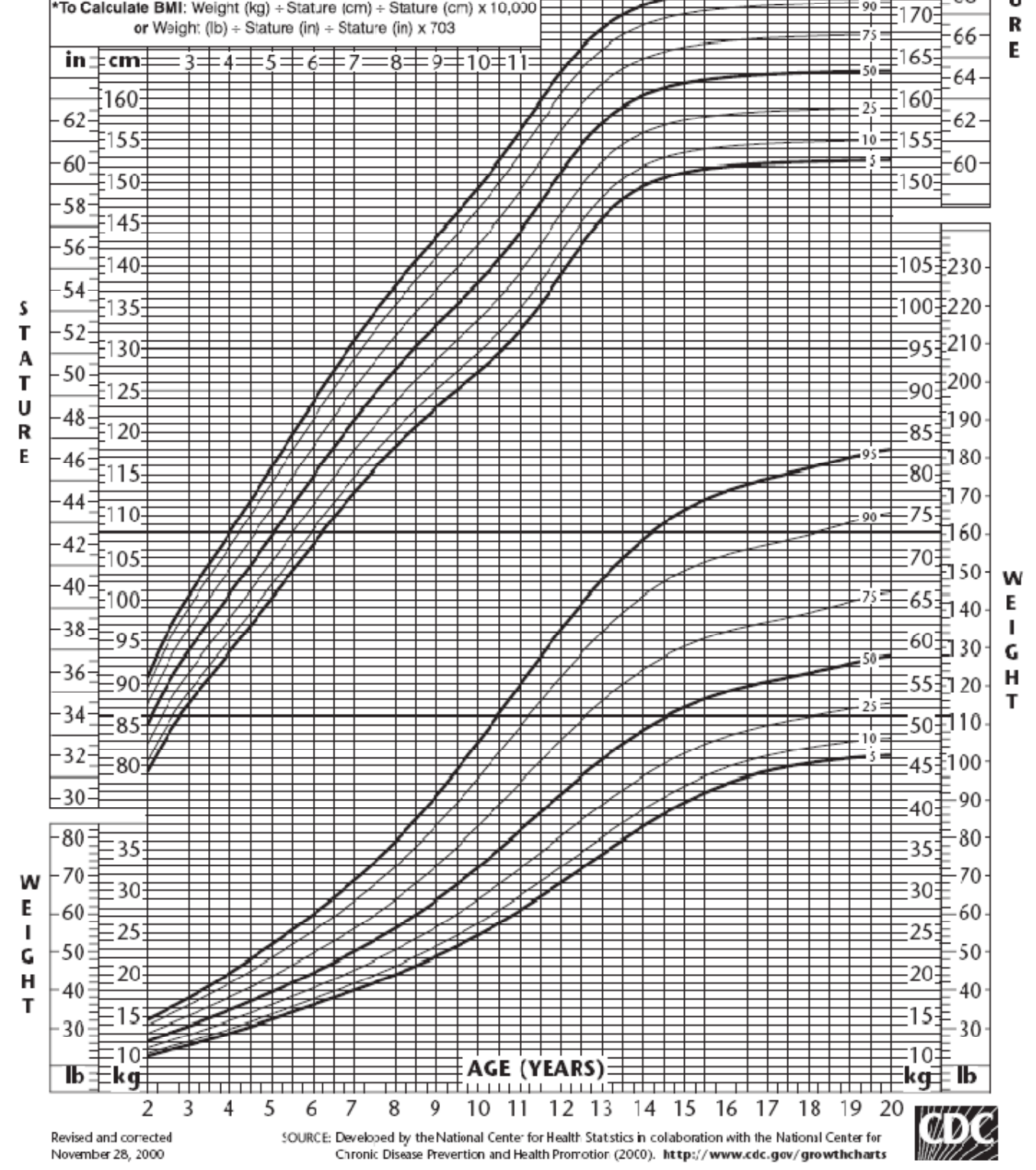

$\begin{array}{lllllllll}12 & 13 & 14 & 15 & 16 & 17 & 18 & 19 & 20\end{array}$

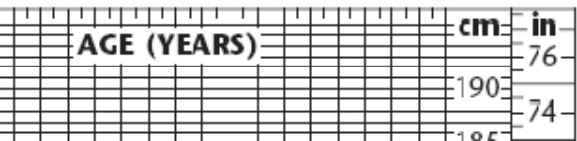

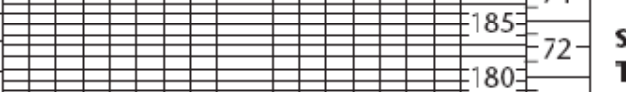
\begin{tabular}{l}
2 - \\
\hline
\end{tabular} 
2 to 20 years: Girls Body mass index-for-age percentiles

NAME

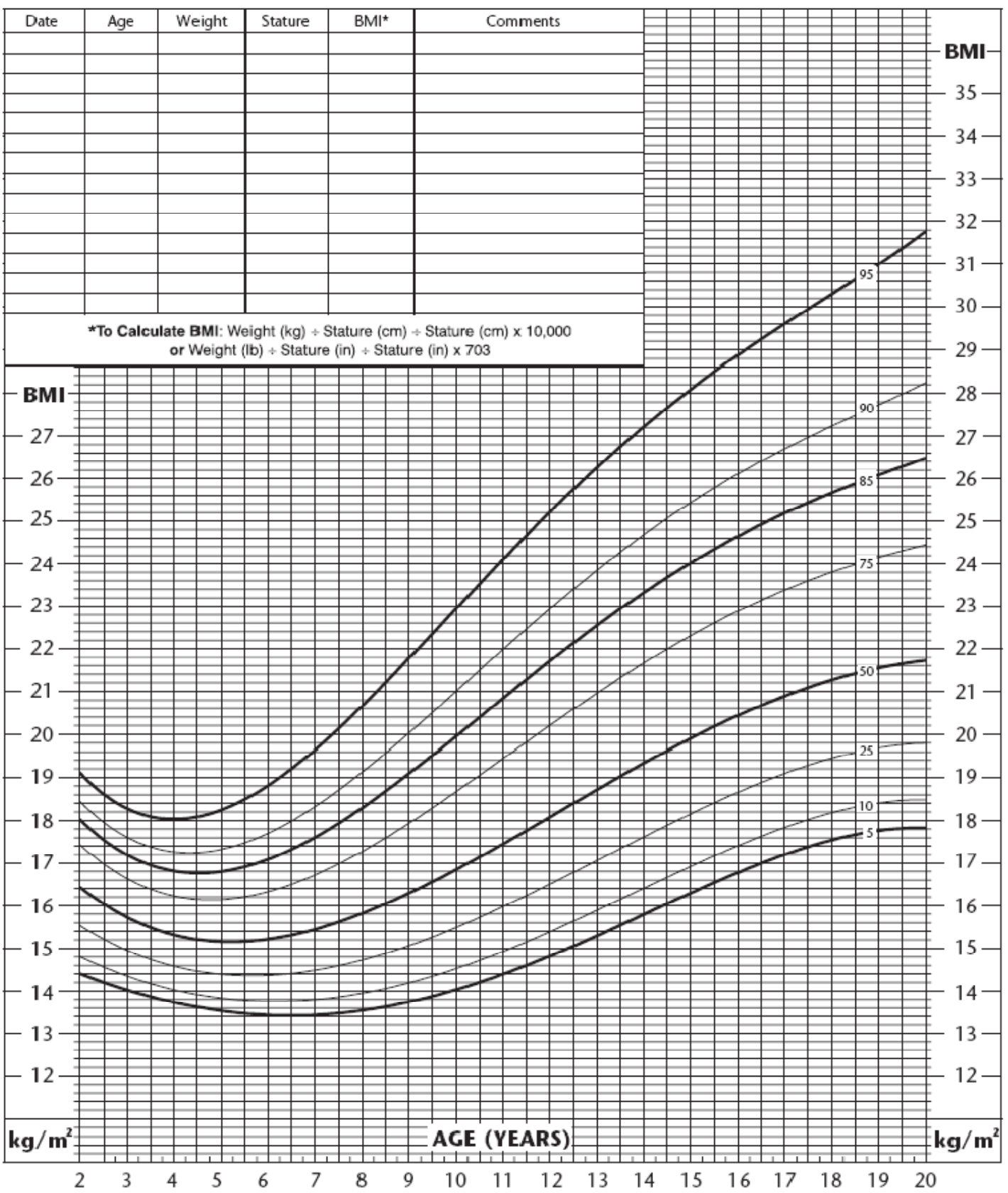

SOURCE: Developed by the National Center for Health Statistics in collaboration with the National Center for Chronic Disease Prevention and Health Promotion (2000). https//www.cdcgov/growthcharts 


\section{Appendix 3: Take Charge, Be Healthy Pre- Post- Nutrition Knowledge Quiz Questions}

\section{Content Questions for Take Charge: Nutrition}

The following questions will be in the Do You Know? quiz section of the Nutrition Topic. Six (6) questions will be randomly selected each time a user takes the quiz. After each response, a programmed response will be displayed that tells the user if the answer is correct, and gives the reason why it is/isn't.

The questions identified with (*) will be used for the pre/post knowledge questions for the Nutrition section.

1. *Whole grain cereals and breads, brown rice, fruits and vegetables are all examples of foods that will provide much needed

a. Carbohydrates in your diet.

$\rightarrow$ That's Right! According to the food guide pyramid, whole grain cereals, bread, brown rice, fruits and vegetables all provide carbohydrates which your body needs for energy.

b. Fats

$\rightarrow$ That's incorrect. According to the Food Guide Pyramid, whole grain cereals and breads, brown rice, fruits and vegetables all provide

c. Protein carbohydrates which your body needs for energy.

$\rightarrow$ That's incorrect. According to the Food Guide Pyramid, whole grain cereals and breads, brown rice, fruits and vegetables all provide carbohydrates which your body needs for energy.

d. Iron

$\rightarrow$ That's incorrect. According to the Food Guide Pyramid, whole grain cereals and breads, brown rice, fruits and vegetables all provide carbohydrates which your body needs for energy.

2. There are the same amount of nutrients (including calcium) in skim (nonfat) milk as in whole milk.
a. True

$\rightarrow$ Great! There is no difference in the amount of nutrients found in skim milk and whole milk. The difference is in fat content and calories.

b. False

$\rightarrow$ Actually, there is no difference in the amount of nutrients found in skim milk and whole milk. The differenced is in the fat content and calories.

3. *It is during the teenage years that the majority of bone mass development occurs, so it is very important for teens to have an adequate amount of in their diets.

a. Fats

$\rightarrow$ Actually, calcium is one of the most important nutrients related to bone mass development. Good strong bones need plenty of calcium.

b. Protein

$\rightarrow$ Actually, calcium is one of the most important nutrients related to bone mass development. Good strong bones need plenty of calcium.

c. Calcium

$\rightarrow$ That's right! Calcium is one of the most important nutrients related to bone mass development. Good strong bones need plenty of calcium.

d. Iron 
$\rightarrow$ Actually, calcium is one of the most important nutrients related to bone mass development. Good strong bones need plenty of calcium.

4. *When the amount of calories consumed (through the foods you eat) is equal to the amount of calories burned (physical activity), it is called

a. Energy Efficiency

$\rightarrow$ Actually, the correct answer is energy balance. Remember, a good balance between physical and healthy diet is the key to a healthy lifestyle.

b. Equal Consumption

$\rightarrow$ Actually, the correct answer is energy balance. Remember, a good balance between physical and healthy diet is the key to a healthy lifestyle.

c. Balanced Calories

$\rightarrow$ Actually, the correct answer is energy balance. Remember, a good balance between physical and healthy diet is the key to a healthy lifestyle.

d. Energy Balance

$\rightarrow$ Great Job! A good balance between physical and healthy diet is the key to a healthy lifestyle.

5. Consistently burning more energy (through physical activity) than you take in (through calories in food) could result in

a. Weight Maintenance

$\rightarrow$ Actually, when you energy balance shifts to more calories being burned (through physical activity) then being consumed, you will lose weight.

b. Weight Gain

$\rightarrow$ Actually, when you energy balance shifts to more calories being burned (through physical activity) then being consumed, you will lose weight.

c. Weight Loss

$\rightarrow$ You're Right! When your energy balance shifts to more calories being burned (through physical activity) then being consumed, you will lose weight.

d. None of the Above

$\rightarrow$ Actually, when you energy balance shifts to more calories being burned (through physical activity) then being consumed, you will lose weight.

6. MyPyramid.gov is a food guide tracker that helps individuals analyze their food choices against national recommendations.

a. True

$\rightarrow$ You're Right! MyPyramid.gov is a great way to see how your food choices compare to that of the national recommendations.

b. False

$\rightarrow$ Actually, MyPyramid.gov is a great way to see how your food choices compare to that of the national recommendations.

7. *If a large bag of chips has 150 calories per $1 \mathrm{oz}$. serving, and there are 8 servings in the bag, how many calories would you consume if you ate the entire bag?

a. 800 Calories

$\rightarrow$ Actually, if you had 8 servings of these chips, you would have consumed 1200 calories. Remember, you multiply the calories in one 
serving by the total servings consumed to find out how many calories you consumed.

b. 1200 Calories

$\rightarrow$ Great Job! 150 calories multiplied by 8 servings is 1200 calories. You can find other information the same way (such as total fat grams consumed).

c. 1500 Calories

$\rightarrow$ Actually, if you had 8 servings of these chips, you would have consumed 1200 calories. Remember, you multiply the calories in one serving by the total servings consumed to find out how many calories you consumed.

d. None of the answers above are correct

$\rightarrow$ Actually, if you had 8 servings of these chips, you would have consumed 1200 calories. Remember, you multiply the calories in one serving by the total servings consumed to find out how many calories you consumed.

8. *Which of the following is NOT a tip for healthy eating?

a. Drink Milk

$\rightarrow$ While drinking milk is a very important part of eating healthy, eating only when you are hungry and eating 3 meals a day with nutritional snacks in between are also important.

b. Eat when you are hungry

$\rightarrow$ While eating when you are hungry is a very important part of eating healthy, drinking milk and eating 3 meals a day with nutritional snacks in between are also important.

c. Eat 3 meals a day with nutritional snacks in between

$\rightarrow$ While eating 3 meals a day with nutritional snacks in between is a very important part of eating healthy, drinking milk and eating when you are hungry are also important.

d. All are good tips for healthy eating

$\rightarrow$ You're Right! Drinking plenty of milk, eating when you are hungry, and eating 3 meals a day with nutritional snacks in between is a great way to be sure you are eating healthy.

9. Eating breakfast first thing in the morning will help you feel better, perform better, and stay awake.

a. True

$\rightarrow$ Way to go! A good healthy breakfast is a great way to start the day. It will help you feel better, perform better, and stay awake!

b. False

$\rightarrow$ Actually, a good healthy breakfast is an important part of each day.

Your body needs the "recharge" of energy that breakfast provides so you can feel better, perform better, and stay awake.

10. *Obesity will not likely be a consequence of poor nutritional habits.

a. True

$\rightarrow$ Actually, poor nutritional habits CAN lead to obesity and other problems.

b. False

$\rightarrow$ That's Right! Poor nutritional habits CAN lead to obesity and other problems.

11. Which of the following is NOT a benefit of eating healthy? 
a. Having more energy

$\rightarrow$ Actually, healthy eating will lead to an increase of energy

b. Becoming overweight or underweight

$\rightarrow$ That's Right! Healthy eating is part of energy balance, and when combined with physical activity, typically results in a healthy body weight.

c. Maximizing your growth potential

$\rightarrow$ Actually, healthy eating will maximize your growth potential as your body is receiving important nutrients needed for growth

d. Feeling good

$\rightarrow$ Actually, healthy eating will give you more energy and will typically cause you to feel better as your body isn't lacking for important nutrients

12. *How much of a food or drink you choose to eat at any given time is called

a. A portion

$\rightarrow$ That's Right! A portion is the amount of food or drink you decide to consume. This can be more or less than one serving.

b. A serving

$\rightarrow$ Actually, a serving is a measured amount of food or drink. Food labels show information for one serving. Not for one portion.

c. Energy Balance

$\rightarrow$ Actually, energy balance is the term used to describe the amount of calories consumed while eating versus the amount of calories burned through physical activity.

d. A nutrition facts label

$\rightarrow$ Actually, a nutrition facts label is the part of the product that contains important information related to an individual serving of that product.

13. A standard set by the US Government that is printed on most packages is called

a. A portion

$\rightarrow$ Actually, a portion is the amount of food or drink that you choose to consume.

b. A generic size

$\rightarrow$ Actually, a generic size is not a standard that is printed on most packages.

c. The Food Guide Pyramid

$\rightarrow$ Actually, the food guide pyramid is not a standard that is printed on most packages.

d. A serving

$\rightarrow$ That's Right! A serving is the standard measured amount of a product, and all information related to a single serving is printed on most packages.

14. A standard serving size for dried fruit ( $1 / 2 \mathrm{cup})$ is about the size of

a. A light bulb

$\rightarrow$ Actually, the standard serving size for dried fruit is about the size of an egg.

b. A softball

$\rightarrow$ Actually, the standard serving size for dried fruit is about the size of an egg.

c. A baseball 
$\rightarrow$ Actually, the standard serving size for dried fruit is about the size of an egg.

d. An egg

$\rightarrow$ That's Right! The standard serving size for dried fruit is about the size of an egg.

15. A standard serving size for milk ( $8 \mathrm{oz})$ is

a. $1 / 2$ cup

b. 1 cup

$\rightarrow$ Actually, the standard serving size for milk is 8 oz. or about 1 cup.

$\rightarrow$ That's Right! The standard serving size for milk is $8 \mathrm{oz}$. or about 1 cup.

c. Size of a soda can

$\rightarrow$ Actually, the standard serving size for milk is 8 oz. or about 1 cup.

d. $1 \frac{1}{2}$ cups

$\rightarrow$ Actually, the standard serving size for milk is 8 oz. or about 1 cup.

16. *A standard serving of pasta is about the size of

a. A grapefruit

$\rightarrow$ Actually, the standard serving size of pasta is about the size of a hockey puck.

b. A hockey puck

$\rightarrow$ That's Right! The standard serving size of pasta is about the size of a hockey puck.

c. An egg

$\rightarrow$ Actually, the standard serving size of pasta is about the size of a hockey puck.

d. A tennis ball

$\rightarrow$ Actually, the standard serving size of pasta is about the size of a hockey puck.

17. *Of the following, which one will you NOT find on a Nutrition Facts food label?

a. Serving size

$\rightarrow$ Actually, serving size is found on all nutrition facts labels (near the top).

b. Servings per package

$\rightarrow$ Actually, servings per package is found on all nutrition facts labels (next to serving size).

c. Calories per serving

$\rightarrow$ Actually, calories per serving are listed on the nutrition facts label.

d. Calories per package

$\rightarrow$ That's Right! Calories per package are not listed on the label, but you can easily determine this number by multiplying the amount of calories in one serving by the number of servings in the package.

18. Of the following, which one will you NOT find on a Nutrition Facts food label?

a. Total Fat

$\rightarrow$ Actually, total fat grams are found on all nutrition facts labels near the middle of the label.

b. Saturated Fat

$\rightarrow$ Actually, saturated fat grams are found on all nutrition facts labels near the middle of the label.

c. Cholesterol 
$\rightarrow$ Actually, the amount of cholesterol in one serving is found on all nutrition facts labels.

d. You will find all of the above

$\rightarrow$ That's Right! You will find all of the information listed above on all nutrition facts labels.

19. Read the label below and answer the questions.

a. *How many servings are in the package?
a. 1
b. 4
c. 8
d. 10

b. *How many calories are in three servings of this product?
a. 90
b. 150
c. 180
d. 270

c. How many grams of saturated fat are in this product?
a. 3
b. 5
c. 0
d. 10

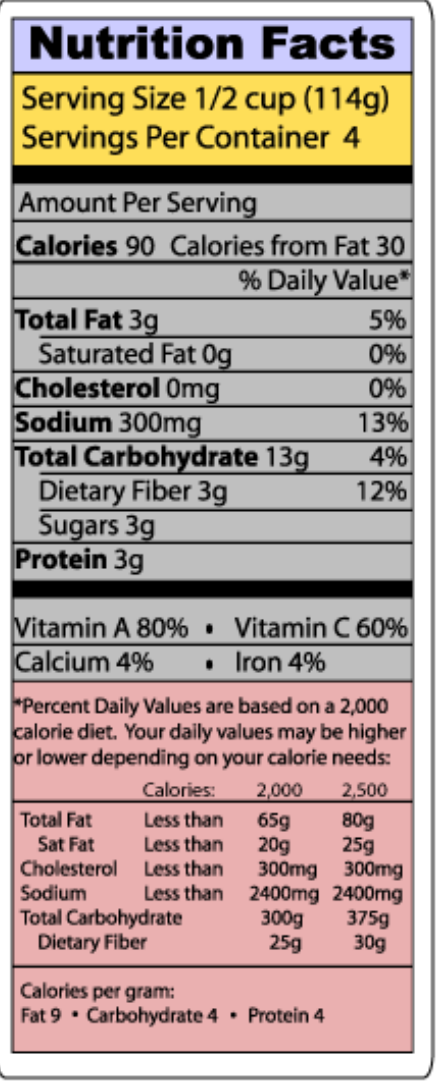


Appendix 4: The Portion Plate

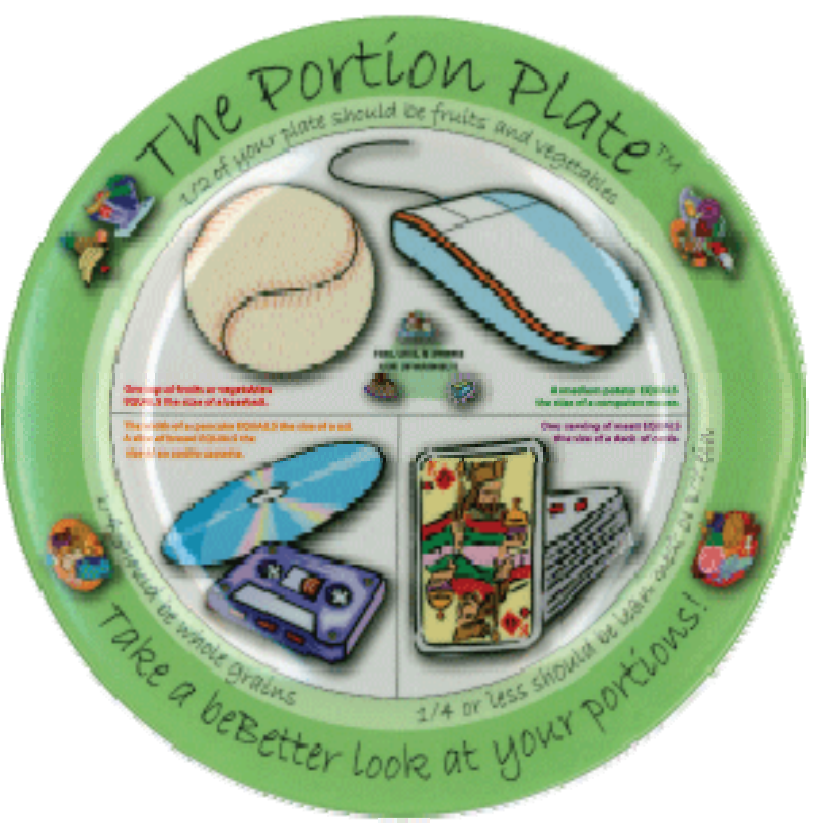


Appendix 5: Nutrition Lesson One, Portion Control

Objectives: Campers will be able to recognize a 'Portion Plate'.

Campers will be able to list portions for at least four foods presented.

Campers will be able to list the food groups represented on a correct

'Portion Plate'.

Materials: Paper Plates

Colored Pencils/ Markers/ Crayons

Food Models

Portion Comparisons (CD, computer mouse, cards, tennis ball, etc.)

Portion Plate

Lesson:

- Opening:

o As a group, can you list the food groups?

o Do you know how many servings of each food group kids your age should be getting daily?

o Does anyone know what the correct portions of these foods are?

- Activity:

o Give each camper 2 plain paper plates and a marker. Ask each camper to draw how they feel a "portioned" plate SHOULD look on the first plate.

On the second plate ask the campers to draw how their dinner plates usually look.

o Once everyone has finished, show the campers what a correctly "portioned" plate looks like. Ask the campers if the plates they drew look different? How?

o Discuss correct portion sizes with campers. Use objects $(\mathrm{CD}$, deck of cards, computer mouse, golf ball, etc.) to convey the correct portion sizes of pasta, meats, fruits, vegetables, etc.)

- Closing: Quiz campers on 'Portion Plate' i.e. What portion of your plate should be covered with vegetables? Protein? Starch?; Where does fruit/dairy fit? 
Appendix 6: Nutrition Lesson Two, Energy Balance and Nutrition

Objectives: Campers will be familiar with all components of the 'Portion Plate'.

Campers will be able to explain the importance of balancing food intake with energy output (exercise).

Campers will be able to fill their plates, following the 'Portion Plate'.

Materials: Portion Plate

Blank Portion Plate template papers

Pens/ Pencils

Copies of cafeteria menu through the end of camp

Lesson:

- Opening:

o How do you choose the foods you eat?

- Availability, cost, taste, friends, family

o How could you improve the balance of your diet?

o Why should you choose to eat a more balanced diet?

o Has anyone tried to fill their plates according to the 'Portion Plate' at mealtime?

o How do you choose your physical activity?

- PE class, friends, siblings, skills

o Do you need to be more physically active? How can you achieve this?

o Why should you choose to be physically active?

- Activity:

o Ask the campers to tell you about the 'Portion Plate'. Pass out the blank portion plate papers, pencils, and a copy of the cafeteria menu to all campers. Ask the campers to plan a meal they would like to eat with the foods being offered at dinner tonight according to the 'Portion Plate.'

o Have campers plan meals using the 'Portion Plate' and cafeteria menus, as time allows. Walk around to review campers' selections, make

- Closing: suggestions and answer campers' questions.

o What are some benefits to eating a more balanced diet?

o Can the 'Portion Plate' be used to help improve your diet? How? 
Appendix 7: Nutrition Lesson Three, Food Labels

Objectives: Campers will be familiar with food nutrition labels.

Campers will be able to use food nutrition labels to make good food schoices.

Materials: Nutrition Label(s)

Enlarged food label

Lesson:

- Opening:

o Why do you choose the foods to eat that you do?

- Convenience, taste, nutrition, family, friends

o Have you ever used a nutrition label before?

- If so, how often do you look at nutrition labels? What do/did you look for? Why?

o What are some hurdles to using the nutritional facts label?

- Don't know how to read them/ what they mean.

o Using an enlarged food label, discuss:

- Calories

- Calories from fat

- Serving size (per container)

- Sugar

- Vitamins/Minerals

- Daily Values (\% DV)

- Good Source (these types of claims are regulated, what do they mean)

- Activity:

o Break campers into four groups; provide each group with the same collection of food nutrition labels. Ask each group to work together to put the foods in order from the greatest amount of various nutrients to the least amount of that nutrient.

- Calcium- $\uparrow$ whole milk, skim milk, orange juice with $\mathrm{Ca}$ (all 30\%); broccoli (4\%) $\downarrow$

- Iron- $\uparrow$ Wheaties (45\%); lean ground beef $(15 \%)$; regular ground beef, refried beans (both 10\%) $\downarrow$

- Sugar- $\uparrow$ regular soda (41g); Cocoa Krispies cereal (14g); Cheerios $(1 \mathrm{~g})$; diet soda $(0 \mathrm{~g}) \downarrow$

- Fat- $\uparrow$ pepperoni (13g); Chicken with skin, mayonnaise (both $11 \%$ ); chicken without skin, mustard (both $0.5 \mathrm{~g}$ ) $\downarrow$

- Closing:

o Do any of these values surprise you? Which ones? Why? By using the nutrition label can you tell which foods are better choices? 


\section{Appendix 8: Grocery Store Tour Outline}

1. Fruits and Veggies: Discuss the benefits of fruits and vegetables in the diet. Example: the darker green the lettuce, the more vitamins and minerals it contains. Please note the importance of variety. Different fruits and vegetables have different vitamins and minerals in them, eating a large variety is the best way to get all the vitamins and minerals your body needs. Fruits and veggies are high in fiber. Foods high in fiber can sometimes decrease the appetite of someone who is trying to lose weight because it can satisfy their hunger for a longer amount of time. Other foods high in fiber are breads, grains, and legumes.

Potatoes can be very healthy. Baked potatoes with toppings can be a healthy and quick meal. Toppings can be chili, veggies, seasoned taco meat with low fat cheese and low fat sour cream, chicken w/ BBQ sauce etc.

Point out that sweet potatoes can be another option of a starch at mealtime. Sweet potatoes are low in calories and high in vitamins and minerals important for skin and eye health.

2. Breads: Stress the importance of WHOLE GRAIN breads, rolls, bagels, etc. Choose labels and compare: $100 \%$ whole wheat to "wheat" bread. If a package does not say $100 \%$ whole wheat chances are the product was made with enriched white flour and caramel coloring to give the wheat breads its dark color.

3. Meats: Discuss lean meats (chicken; turkey) vs. less lean meats (hamburger, sausage, salami). Give examples. Some ways of cooking meats are more healthful than others i.e. baking, broiling and grilling. Meat is a great source of protein and some minerals, such as: iron. For ground meat and red meat, point out that the white or marbling of fat throughout the meat, the higher in fat it will be.

4. Sandwich (Lunch) Meat: The amount of sodium in these types of meats is usually very high. Again some meats are better choices than others. Turkey and roast beef can be a pretty good choice, while bologna, salami, and olive loaf are less healthy choices. Briefly go over better condiments to use for sandwich or tuna salad etc. Point out the high caloric, fat, and sodium content in Lunchables type products.

5. Beans/ legumes, canned veggies, mixed-boxed foods, etc: (aisles \# 3 \& 5) Beans/legumes i.e. Black, Red, Pinto, Garbonzo, etc., are high in protein and fiber, low in fat and low in cost. Because beans, etc. are high in protein and fiber they can really help to keep you full for a long time.

Ask if any of the campers have ever made products like Rice-r-Roni, Liption flavored noodles, boxed macaroni and cheese, etc. Give ideas on how to prepare these kinds of box mixes more healthful by using skim milk to lower fat, skipping the butter all together, etc. Rice (converted) is easy to cook and can be a foundation for stir fried meals. Brown rice is a whole grain, is full of fiber and flavor! 
Easy snacks to put in BACKPACK are cereal bars, dry cereal, granola bar, trail mix, chex mix, pudding, bagels, crackers, piece of fruit (individual size).

6. Fruit Juices: Emphasize the importance of looking at the label and seeing that the juice is $100 \%$, not $10 \%$; all juices are not created equal. You can tell if the juice is not $100 \%$ juice, the giveaway is that it will be labeled as a fruit drink or fruit punch. Juicy Juice is $100 \%$ fruit juice; HiC fruit drink is not. $100 \%$ fruit juice can be a great choice but caution the campers that juice does not contain fiber but often has the same number of calories as the fruit itself. Offer ideas to lower juice calories by adding a little water to the juice or adding soda water to make a spritzer!

7. Cereal aisle: Pick out 2 cereals to compare (one sugary cereal- ask the campers a cereal they typically eat and one healthier cereal). Compare the cereals on: sugar, fiber and fat content. For a marketing ploy, the food industry puts the sugary/sweet cereal on the bottom for children to have easy access (at children's eye level). Cereals that are eye level will typically be lower in sugar and higher in fiber. Cereal can be a healthy snack any time of the day, also cereal bars, Instant Breakfast, granola bars etc.

8. Soda Sodas and sugary drinks (Kool-Aid) are empty calories. Empty calories are calories that do not provide any vitamins or minerals to your body and if you consume too much can make you gain weight.

Explain that it is a good idea to carry a container of water with them throughout the day to maintain proper hydration.

9. Snacks: Give them ideas of low fat snacks i.e., frozen yogurt, ice milk, reduced fat ice cream, $100 \%$ juice bars, etc.

Salty snacks: baked chips, pretzels, Chex mix, trail mix, etc.

10. Milk: Go over the differences in milk, stress that they ALL (skim, whole, chocolate, etc.) contain the same amount of protein, vitamins, and minerals, but the fat content is different. Dairy and especially milk consumption is very important at this age to develop strong bones and prevent injury later in life. Most people should try to drink skim or $1 \%$. Explain the Kroger Plus or Ultra Skim is skim milk that tastes like 2\%.

11. Cheese \& Yogurt: Go over different types of cheeses which come in low fat or reduced fat. Mozzarella is one of the lowest in fat and cheddar is one of the highest in fat. Go over the different types of yogurt. Regular vs. low-fat; pro-biotic vs. not; etc. Most yogurts contain about the same amount of calcium as an 8 oz. glass of milk (300 $\mathrm{mg}$ ). Explain that yogurt would be a good snack because of the combination of protein and carbohydrates.

12. Eggs Discuss how to make egg dishes (scrambled eggs, omelets) with only egg whites, or using just one yolk. Adding some chopped veggies to eggs can make a satisfying meal any time of day! Stress that the protein in an egg is in the white part, not in the yolk. The yolk contains fat and cholesterol. 
13. Frozen food: Try to emphasize limiting high fat frozen food items (pizza, cheese sticks, etc.) If they want pizza, tell them to try the Bagel Bite Pizza, or to make their own at home, so that they can control what type of toppings are on it i.e. Canadian Bacon, Veggies, and low fat mozzarella cheese. Point out the Lean Cuisines made with whole grains, Healthy Choice, and Smart Ones options. Frozen vegetables are fast and easy to fix in the microwave.

Explain that the frozen juices should be $100 \%$ juice. Compare $100 \%$ orange juice to a frozen punch.

14. Organic Foods: Point out alternative healthy sources of food from this section. These are food items that maybe more expensive but have fewer additives and preservatives than other processed foods such as regular chips, cookies, ice creams, vegetables and meats. Organic produce does not contain more vitamin/mineral than nonorganic produce.

*You can ask if any of their families buy organic, my guess is that they don't but at least explain the organic concept to them. And please try to avoid the diet pills/products!

Most of all, stress the importance of MODERATION! Methods of food preparation can make a healthy food, unhealthy (i.e. fried zucchini). 
Appendix 9: Instructions for Completing an Accurate Daily Food Record

- Record everything you eat and drink for 3 days. Include the date and day of the week at the top of each form. Record your intake for 2 weekdays and 1 weekend day from the time you wake up to the time you go to bed.

- Use a separate form for each day. Use more than one form if needed for one day, but begin a new form for each new day.

- Keep it with you. Carry the food record with you during the day. It is surprisingly difficult to recall what you ate days or hours later.

- Include details. Record anything added to the food such as sugar, ketchup, margarine, or ranch dressing.

- Describe combination foods. If you are eating a combination food such as pizza with various toppings, make sure to record all ingredients. Record brand names for packaged foods and record restaurant name for foods eaten away from home.

- Estimate serving size. To the best of your ability, estimate the serving size. Use the serving size on the food label if available. Use measuring cups and spoons at home. If you are uncertain, estimate using familiar objects. For example, you can use "palm of my hand" to estimate the size of a chicken breast or "baseball" to estimate a serving of ice cream.

- Record time. Record the approximate time each meal or snack is eaten.

- Write down beverages. Be sure to record all beverages that you consume. This includes no-calorie drinks such as diet sodas, unsweetened tea and water.

- Write down any vitamin or other supplements that you take. Include the brand name and amount you took.

- Bring the record with you to camp! 


\section{Daily Food Record Form}

\begin{tabular}{|c|c|c|c|}
\hline Time & $\begin{array}{l}\text { Food/Drink } \\
\text { Type of food, brand name, } \\
\text { restaurant }\end{array}$ & $\begin{array}{l}\text { Method of Preparation } \\
\text { Description, product label or } \\
\text { recipe }\end{array}$ & $\begin{array}{l}\text { Amount } \\
\text { Tsp, tbsp, cup, } \\
\text { oz, weight or } \\
\text { portion }\end{array}$ \\
\hline & & & \\
\hline & & & \\
\hline & & & \\
\hline & & & \\
\hline & & & \\
\hline & & & \\
\hline & & & \\
\hline & & & \\
\hline & & & \\
\hline & & & \\
\hline & & & \\
\hline & & & \\
\hline & & & \\
\hline & & & \\
\hline & & & \\
\hline & & & \\
\hline & & & \\
\hline & & & \\
\hline & & & \\
\hline & & & \\
\hline & & & \\
\hline & & & \\
\hline & & & \\
\hline
\end{tabular}


Appendix 10: Camp NEW You Master Schedule

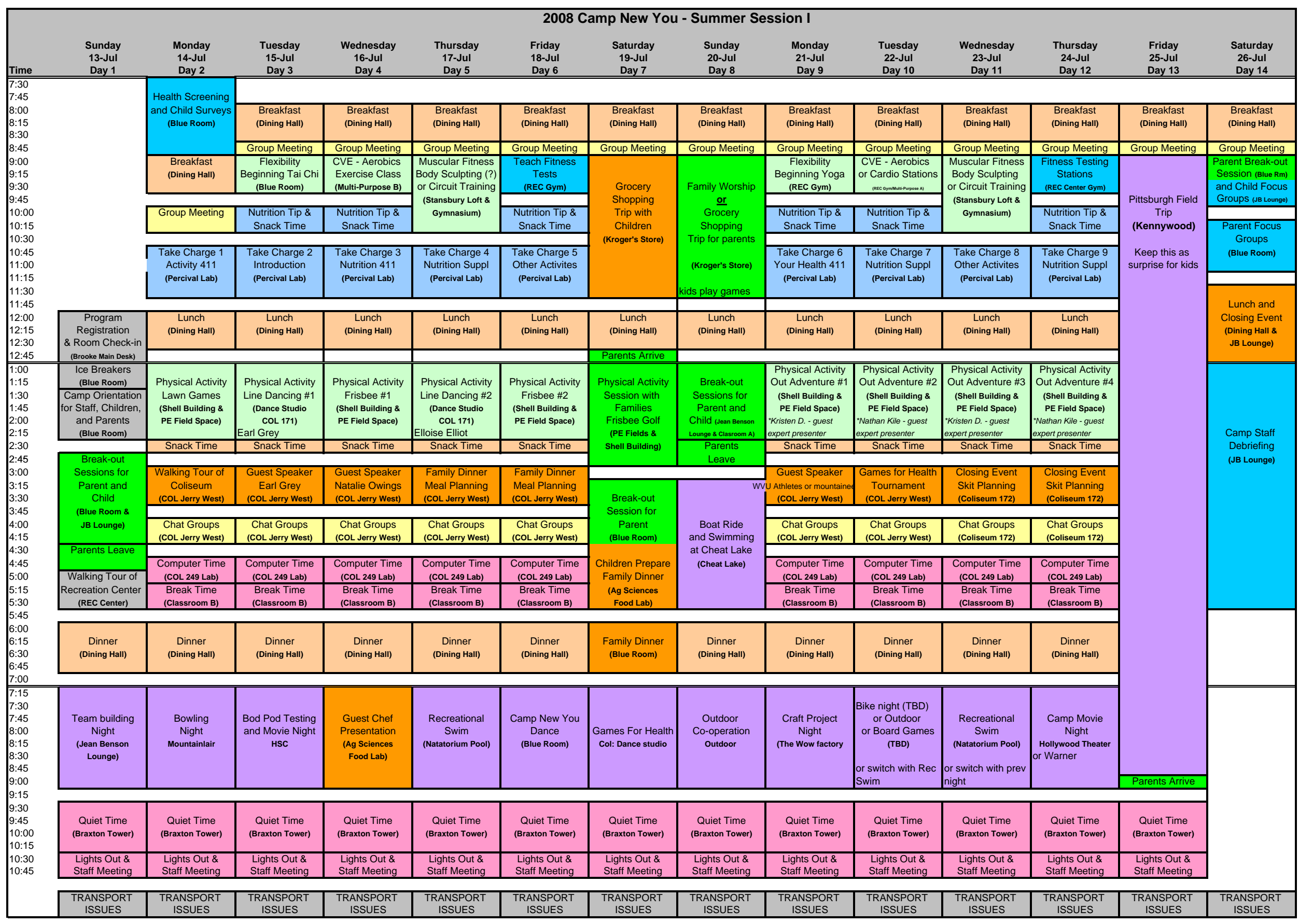

*MASTER CAMP SCHEDULE REVISED 07/09/08 
Appendix 11: Camp NEW You Cookbook 2008

Camp New

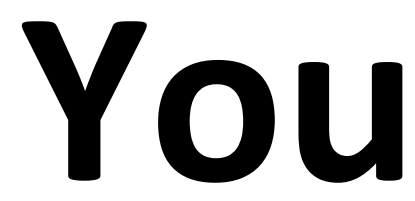

Healthy Snacks for Active Kids

By Heidi “Snacks" Schoeppner

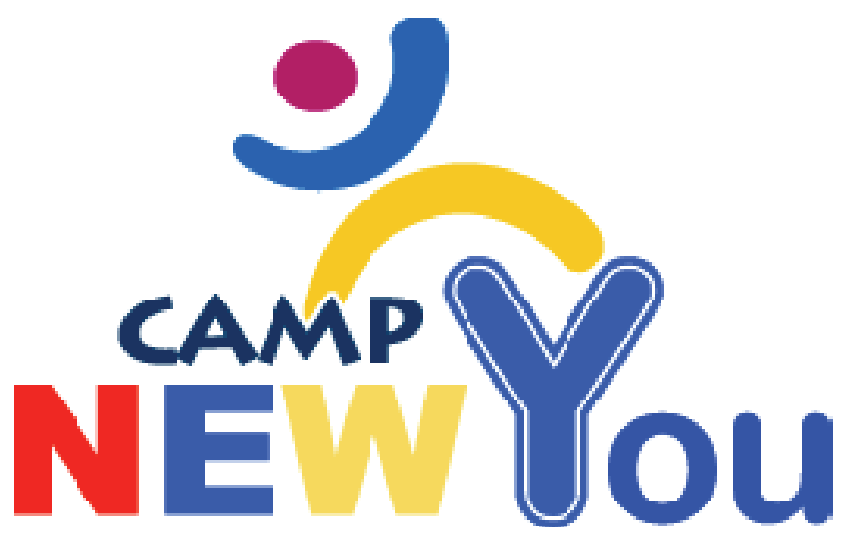




\section{CAMP NEW YOU - FAMILY DINNER}

\section{Snack's Cake:}

1 box of cake mix(w/o pudding)

1 can (12 oz) zero calorie soda

Mix ingredients well, pour into a greased cake pan and bake according to the package's instructions.

\section{Fitztastic's Green Beans:}

2 Tbsp Olive Oil

$1 \mathrm{lb}$. green beans, fresh or frozen

Preheat oven to $450^{\circ}$. Wash green beans. Cover a cookie sheet with foil. Toss green beans with olive oil, spread into a thin layer across the cookie sheet. Roast the green beans for 10 minutes. Take out of oven and re-toss green beans, add any additional seasons to taste (examples: garlic salt, soy sauce, red pepper flakes, etc.) Roast green beans for an additional 10 minutes. Serve.

\section{New You Turkey Loaf:}

2 tsp vegetable oil

1 cup finely chopped onion

$3 / 4$ cup finely chopped carrot

$1 / 2$ cup finely chopped green onions

$1 / 2$ cup finely chopped red bell pepper

2 garlic cloves, minced

$2 \frac{1}{2} \mathrm{lbs}$. ground raw turkey breast

1 cup dry bread crumbs

$1 / 3$ cup ketchup

1 tsp salt

1 tsp pepper

$1 / 4$ tsp ground nutmeg

$1 / 4$ tsp ground cumin

$1 / 4$ tsp ground coriander

4 egg whites, lightly beaten

Vegetable cooking spray

$1 / 2$ cup ketchup

3 Tbsp brown sugar

Preheat oven to $350^{\circ}$. Heat oil in a large nonstick skillet over medium heat until hot. Add onion and next 5 ingredients; sauté 5 minutes or until tender. Combine onion mixture, ground turkey, and next 8 ingredients in a large bowl; stir well (mixture will be wet). Shape meat mixture into a $9 \times 5$ in loaf on a broiler pan coated with cooking spray. Bake at $350^{\circ}$ for 30 minutes. Combine $1 / 2$ cup ketchup and brown sugar; brush over turkey loaf. Bake an additional 30 minutes or until done; let stand 10 minutes before slicing. 


\section{CAMP NEW YOU - HEALTHY SNACKS}

Muscle's Trail Mix

1 Tbsp Chocolate Chips

Raisins

Frosted Mini Wheats

Cheerios

Pretzels

Mix all ingredients together and enjoy!

\section{Justine's Tennis Snack Pizza}

1 whole-wheat English muffin, halved

2 tbsp pizza sauce

$1 / 4$ cup non-fat or low-fat mozzarella cheese

4 pieces turkey pepperoni

Top each English muffin half with 1 tbsp pizza sauce, half of the cheese, and 2 pieces of pepperoni. Toast under the broiler until the cheese is nice and bubbly.

\section{I'm a Star-Smoothie}

1 cup skim milk

$1 / 2$ cup fat free vanilla yogurt

$1 / 2$ cup each of your favorite frozen or fresh berries or other fruits (i.e. peaches, bananas, or pineapple)

In a blender, mix all ingredients until smooth.

\section{Chef Tim's Tomato Salad}

1 sliced tomato

1 Tbsp Balsamic vinegar

1 Tbsp extra virgin olive oil

2 Basil leaves

Spread the sliced tomatoes on a platter and drizzle the vinegar and olive oil over top.

Tear the basil into small pieces and sprinkle over the tomatoes and then serve!

\section{Chef Tim's Pineapple Chicken}

$1 \mathrm{lb}$ skinless and boneless chicken breasts cut into small strips

$1 / 2$ onion, sliced

$1 / 2$ of a fresh pineapple (or 2 cups canned pineapple)

2 tbsp olive oil

In a hot pan brown the chicken in the olive oil. When the chicken is almost done add the pineapple and cook until the pineapple is soft. Add salt and pepper to taste and serve over brown rice.

\section{Chef Tim's Pepper and Chicken Stir Fry}

$1 \mathrm{lb}$ skinless and boneless chicken breasts cut into small strips 
1 red pepper cut into small strips

1 green pepper cut into small strips

1 red onion, sliced

2 tbsp olive oil

In a hot pan brown the chicken in the olive oil. When the chicken is about half way done add the vegetables and cook until the chicken is no longer pink and the vegetables are softened. Add salt and pepper to taste and serve over brown rice.

\section{Big Dog's Morning Wake-up Parfait:}

1 cup low-fat vanilla yogurt

$1 / 2$ cup mixed berries, fresh or frozen

2 Tbsp granola cereal

Put yogurt in a bowl, top with berries then granola. 